\title{
La Puerta del Aceituno
}

\author{
$M^{a}$ del Carmen Pérez Martínez * \\ Antonio López Marcos* \\ Miguel Angel de Dios Pérez *
}

\section{INTRODUCCIÓN}

La intervención arqueológica en el antiguo parque de Bomberos, última función a la que fue dedicado el solar, se inicia en el año 1999 , debido a la redacción de un proyecto para construir un espacio escénico, en el que se prevé un aparcamiento subterráneo y por tanto grandes movimientos de tierra que afectarían de forma inevitable a los restos arqueológicos que presumiblemente se localizasen en el solar que estaba protegido con un nivel $A$ dentro del Plan de Protección y Reforma Interior del Casco Histórico.

La documentación arqueológica ha sufrido un largo proceso finalizando en el 2002. A lo largo de estos años se han realizado tres campañas de excavación en las que se plantearon objetivos distintos en función del nivel de conocimiento que se tenía del solar; la primera intervención ' se ejecutó en el año 1999, el objetivo de la misma era realizar una fase de sondeos aleatorios para comprobar la estratigrafía y el estado de conservación de los posibles restos que hubiese en el solar. Se documenta una ocupación desde época prehistórica hasta el S. XX (con algunos hiatus). De los restos documentados en la misma destacan los de una torre en forma de "D" en el lado $W$, que junto a la torre y fragmento de muralla que forman parte del límite SE del solar podían conformar la "Puerta del Aceituno".

La excepcionalidad de esta estructura, motivó que la segunda fase de excavación ${ }^{2}$ se concentrara en esta zona, para documentar en extensión todos los restos, confirmar el estado de conservación de la torre, la existencia de la puerta, y valorar la idoneidad de su integración en el nuevo proyecto.

Finalmente la tercera fase ${ }^{3}$ se plantea como una intervención extensiva para obtener una visión global de toda la zona.

\footnotetext{
* Arqueólogos

I Financiada por el Ayuntamiento de Jaén. La dirección técnica fue de Miguel Angel de Dios Pérez y Ma Angeles Royo Encarnación, Informe de la Intervención Arqueológica de Urgencia en el Solar del Antiguo Parque de Bomberos. Jaén. (PB/99). Archivo de la Delegación Provincial de la Consejería de Cultura. Jaén. La ejecución de la obra se hizo a cargo de la empresa ARQUEOTEC, S.A.

2 Financiada por la Consejería de Cultura de la Junta de Andalucía a través de su Delegación Provincial. La dirección facultativa estuvo a cargo de Miguel Angel de Dios Pérez, Intervención arqueológica de urgencia en el solar del Antiguo Parque de Bomberos. Jaén. $2^{a}$ fase (PB/00). Archivo de la Delegación Provincial de la Consejería de Cultura. Jaén. La ejecución de la obra fue llevada a cabo por la empresa ARQUEOTEC, S.A.

3 Esta tercera fase ha sido financiada por el Ayuntamiento de Jaén. La dirección técnica ha estado a cargo de M $^{a}$ del Carmen Pérez Martínez y Antonio López Marcos, Excavación Arqueológica de Urgencia en el Antiguo Parque de Bomberos (Jaén). $3^{a}$ Fase (Mayo - Julio 2002). Archivo de la Delegación Provincial de Cultura de la Junta de Andalucía. La ejecución de la obra se llevó a cabo por la empresa TERRAELVIRA, Empresa Constructora.
} 


\section{EL ENTORNO}

Este importante solar de $6.826 \mathrm{~m}^{2}$, se ubica en las faldas del Cerro de Sta. Catalina y presenta grandes irregularidades. Actualmente vemos una superficie relativamente explanada fruto de las intervenciones realizadas principalmente en el siglo XX: por un lado la excavación de parte del solar al sur para ubicar la antigua escuela de enfermeras y por otro lado los fuertes procesos de relleno que se hicieron para la construcción del parque de bomberos (Lámina I). Durante las distintas campañas de excavación, se ha detectado una fuerte elevación de los niveles de uso a lo largo de las distintas épocas.

A pesar de esta regularización del terreno en época contemporánea, aún podemos observar fuertes desniveles altimétricos desde la zona más alta hasta la calle Millán de Priego; así la mayor parte del solar que coincide con la explanada del parque de bomberos se encuentra alrededor de los 57I,50 m de altitud. Al sur se localiza un terraplén de acusada pendiente que desciende de sur a norte, donde se alcanzan los $580 \mathrm{~m}$ en su punto mas alto, mientras que al Este, en la zona que sirve de acceso al aparcamiento de S. Juan de Dios desde la calle Millán de Priego, la altitud absoluta alcanza los 57I y desde aquí se desciende hasta la cota más baja de la calle Millán de Priego. En definitiva entre el punto más alto y más bajo hay una diferencia de 9 metros, a lo que habría que sumar los 5 metros de potencia arqueológica.

El solar esta delimitado actualmente por las calles Carretera de Córdoba, Millán de Priego, Borja y Molino Condesa; al Este y Sudeste del solar se localizan, respectivamente, un ala abandonada del antiguo Hospital de S. Juan de Dios, y la parte rehabilitada del mencionado Hospital que hoy es sede del Instituto de Estudios Giennenses ${ }^{4}$. El límite más meridional lo constituye el edificio anexo del Colegio Ruiz Giménez.

Pero la situación urbanística actual difiere sustancialmente de la del siglo pasado. En el plano de 1887 podemos constatar que perpendicular a la calle Magdalena Baja existía un vial conocido como Callejón de la Muralla ${ }^{5}$ por el que posiblemente discurría el trazado de la muralla medieval, realizando un importante quiebro hacia el norte para enlazar con el tramo conservado en la carretera de Córdoba donde observamos que se representan dos torres circulares.

El solar objeto de nuestro estudio estaba incluido parcialmente en dos manzanas de casas y una zona sin urbanizar a la que se denomina como Campillejo de las Murallas. La primera manzana, de morfología alargada está delimitada hacia el Este por la C/ Sta. Úrsula ${ }^{6}$ que desemboca en el Poyato ${ }^{7}$ que se abre hacia la $\mathrm{Cl}$ de los Morales, actual Millán de Priego. El límite Oeste viene marcado por la desaparecida Cl Atienza que atravesaría perpendicularmente el solar hasta el Campillejo de las Murallas desde un callejón sin salida denominado C/ Condesa ${ }^{8}$; este vial fragmentaría la segunda gran manzana que desde la Iglesia de la Magdalena ocuparía gran parte de la actual calle Molino Condesa.

En la cartografía posterior consultada ${ }^{9}$, esta situación urbanística se mantiene en 1903 y 1931, aunque ya a principios de siglo se puede reconocer el volumen construido de la alma-

\footnotetext{
4 Dependiente de la Diputación Provincial.

5 Archivo Histórico Municipal.

6 Actualmente esta calle no tiene salida.

7 El Poyato es un campillo muy habitual en la morfología urbana de Jaén; se trata de "minúsculas plazuelas" o ensanchamientos que se abren en el abigarrado entramado de calles estrechas.

8 El callejón Condesa con dirección Este - Oeste se conserva actualmente con salida a la actual Molino Condesa y está delimitado por el Convento de Sta. Ursula y uno de los edificios que forman parte del Colegio Público Ruiz Giménez.

9 Archivo Histórico Municipal.
} 
zara localizada posteriormente en la intervención arqueológica y que ocuparía parte del Campillejo de las Murallas; no será hasta mediados del siglo XX (1945 aproximadamente ${ }^{10}$ ) (Fig. I) cuando empecemos a detectar pequeños cambios, aunque se mantiene la configuración urbana, se ha perdido la toponimia de la C/ Atienza, por lo que se encontraría prácticamente en desuso y parece intuirse el replanteo de una parte del vial que posteriormente sería Molino Condesa.

Por tanto, es a partir de los años 50-60 cuando se produce una auténtica alteración del entorno con la desaparición de antiguos viales y la apertura de otros nuevos como Molino Condesa y la construcción de la Escuela de Enfermeras (Fig. 2).

\section{LOS DATOS PREVIOS}

El interés y las perspectivas que despertaba este solar están avaladas no sólo por la amplitud del mismo (no es fácil encontrar solares de estas dimensiones dentro de un casco histórico como el de Jaén), sino también por su proximidad al centro neurálgico de la ciudad histórica.

Sobre la etapa romana y medieval contamos con estudios que sintetizando toda la información disponible de intervenciones arqueológicas, hallazgos casuales y fuentes escritas, nos ofrecen una fisonomía muy aproximada de la ciudad en las distintas épocas.

En época romana '", nuestra área de estudio se encontraba en el sector noroccidental del municipio Flavio Aurgitano, a juzgar por los resultados obtenidos en la cercana C/ Borja ${ }^{12}$ donde se localiza un fragmento de la muralla romana que se fecha en el siglo I y se abandona en el
S. II; a partir de estos momentos se convierte en un vertedero hasta época almohade con la construcción de las murallas islámicas más adelantadas aprovechando el tramo romano para generar un foso entre ambos lienzos. Sobre la base de estos resultados, parecia probable que la muralla romana discurriese por el solar o parte del mismo en condiciones similares.

Junto a las evidencias arqueológicas, en el entorno más inmediato del solar se han localizado varias referencias de esta época: en la Fuente de la Magdalena aparecieron restos epigráficos y dos esculturas romanas; en la calle del Poyato, "próxima a la Puerta del Aceituno", fue hallada un ara romana cuyo estudio realizó Bonsor; la inscripción CIL II 336 I, extraída de su ubicación original, debió pertenecer a las termas situadas junto al Convento de Sta. Ursula, en esta se alude a la creación de jardines de cierta extensión junto a las mismas; en el denominado Huerto de Cárdenas, se localizaba el segundo acueducto de Aurgi.

También en las proximidades de nuestra zona de estudio se cuenta con datos fiables que parecen ubicar una necrópolis entre el área de la Puerta de Martos, la Puerta del Aceituno y el residencial las Almenas de donde proceden algunas inscripciones funerarias que no parecen ser desplazadas.

Las noticias sobre el periodo visigodo son más escasas. Los datos que se tienen hasta el momento indican una clara reducción del recinto urbano aunque la "actividad ciudadana" no desaparece; no obstante, lo que parece desprenderse de los datos de los que se dispone actualmente, es que el solar podría estar despoblado en estos momentos.

En el "Huerto de Cárdenas" fue localizado un capitel visigodo por Cazaban ${ }^{13}$, muy próxi-

\footnotetext{
10 Cartografía realizada por el Ingeniero geógrafo Antonio Revenga. Archivo Histórico Municipal.

I I Serrano Peña, J.Li; Memoria de Licenciatura. Inédito. Es el estudio más completo que actualmente existe sobre la configuración de la ciudad en época romana.

12 Zafra, 1992

13 Cazaban, 1919.
} 
mo a este solar. De época tardorromana y visigoda en las inmediaciones del solar y de forma dispersa, se han localizado varias inhumaciones como en la C/ S. Juan de Dios n. ${ }^{\circ}$ I, intervención ${ }^{14}$ realizada en 1993 donde se documentaron restos de una vivienda almohade y de una inhumación bajo el pavimento de la misma, claramente anterior, con una cronología que puede centrarse en estas fechas; otro caso sería la inhumación infantil en fosa simple, rompiendo los niveles de pavimento claramente datado en el S.V, localizada en el Palacio de los Uribe ${ }^{15}$.

En el n. ${ }^{\circ} 2$ de la Plaza de Cambil ${ }^{16}$, muy próximo al solar que nos ocupa, se realizó una intervención arqueológica donde bajo los niveles de aterrazamiento almohade se localiza la existencia de un arroyo que se mantuvo como tal hasta el siglo VII, momento en el que se rellenó con abundantes restos cerámicos, de factura tosca, fechables gracias a una moneda de Wamba.

De época islámica las evidencias más claras de la ocupación del solar es la presencia física de restos de la muralla y una torre circular restaurados por D. Luis Berges así como su cercanía al centro administrativo y religioso de la ciudad, consolidado a partir del S. IX con la construcción de la mezquita aljama por Abderraman II en su programa de reforzamiento del papel del Estado.

No obstante, por los datos obtenidos en las excavaciones realizadas en diferentes puntos de la ciudad, la cronología del trazado de la muraIla que actualmente conocemos es del S. XII, a excepción de algunos fragmentos localizados en el tramo denominado como Muralla Norte ${ }^{17}$.

Desde la Puerta de Martos, la muralla discurre por la calle Magdalena Baja entre la medianería de las casas de este vial con la carretera de Córdoba. Se ha detectado la presencia de algunas torres en su recorrido como la localizada en el n. ${ }^{\circ} 6$ de esta calle ${ }^{18}$; es probable que desde este punto, la muralla hiciese un giro hacia el norte, ya que según $M^{a}$ Soledad Lázaro, desde la calle Magdalena Baja, la muralla atraviesa un barranco ${ }^{19}$ para enlazar con los restos aún visibles de la carretera de Córdoba, que avanzarían por nuestro solar hasta enlazar con la puerta del Aceituno que ella sitúa en la plaza de Cambil.

Aunque a priori no podíamos conocer el grado de ocupación humana de nuestra zona de estudio, parecía probable que esta siguiese una dinámica similar a la del solar delimitado por la calle Fernando IV, Hornos Franco, S. Andrés y Millán de Priego ${ }^{20}$, con una ubicación similar al nuestro, muy próximo a la muraIla. Este espacio se urbaniza en el S. XII, construyendo varias viviendas, algunas de ellas casi pegadas a la muralla, lo que es un índice claro del proceso de macización que sufrió la ciudad en este siglo ${ }^{21}$; de idéntica cronología son las viviendas documentadas en el solar $n .^{\circ}$ I de la C/ S. Juan de Dios y C/ S. Miguel 22 n. ${ }^{\circ}$ 4-6-8, o las canalizaciones de la calle Escalerillas ${ }^{23}$.

Con la rendición del rey lbn al Ahmar y la entrada de Fernando III en Yayyan se establece un nuevo orden social en la ciudad, si bien,

\footnotetext{
14 Pérez, 1994.

15 Cano, 1994.

16 Zafra, 1992.

17 Castillo y Cano, 1993.

18 Esteban y Pérez, 1992.

19 A.M.J.A.C. 1660, abril 5; nota extraída de Ma Soledad Lázaro "Desarrollo de la ciudad de Jaén hasta I600".

20 Castillo, Marín, Pérez y Zafra, 1990-1991.

2I Salvatierra et alii, 1993.

22 Pérez, 1992.

23 Marín, 1991.
} 
su configuración urbana no debió de sufrir cambios importantes hasta la llegada del Condestable D. Miguel Lucas de Iranzo, quien junto a su preocupación por el embellecimiento y mejora de las condiciones higiénicas, tomó importantes medidas para el fortalecimiento de las defensas de la ciudad; en el tramo entre la puerta de Martos y la puerta del Aceituno, el Condestable hizo levantar cinco molinos para abastecer de harina la ciudad y "para guarda y defensa de los dichos molinos, mandó fazer desde las Peñuelas, baxo de la Puerta de Martos, fasta la cava que llega al adarve, una cava; do mando poner muchos mandeletes. E iva por el camino que va debaxo de las dichas peñuelas, fasta la puerta del Azeituno, otra cava bien fuerte. La qual, asi mesmo, mandó fortificar con muchos mandeletes y tapiales" 24.

Al parecer la única construcción importante realizada en el entorno antes del siglo XVI fue el hospital de la Misericordia, enclavado en la collación de S. Miguel y fundado antes de 1499. En 1619 el Cabildo Civil, que nombraba anualmente como patrón de esta fundación a un Caballero Veinticuatro de la ciudad, decidió fusionarlo con otro más pequeño, fuera de la puerta de Martos, y entregarlo a la Orden de S. Juan de Dios ${ }^{25}$.

En época moderna y contemporánea se comienza la ruptura de la muralla de la ciudad para hacer más fluida la comunicación intraextramuros, sin embargo perduran durante toda la edad moderna a pesar del continuo deterioro de las mismas, sobre todo a partir del S. XVIl; en las actas capitulares de este siglo, son numerosas las noticias sobre su ruina y las dificultades para su mantenimiento.

En cuanto al nivel de población, el S. XVII es una centuria de auténtica decadencia, no obstante, se constata la consolidación de varios núcleos de población en los arrabales gracias a la fundación de nuevos conventos. Concretamente nuestra zona de estudio es uno de los arrabalejos que menor incremento sufre a lo largo del siglo XVI siendo ocupada en su mayor parte por huertas ${ }^{26}$. No debió ser así en el siglo XVII ya que según Coronas Tejada, en la epidemia de peste de I68I "El concejo municipal consideró que la mejor forma de defenderse del contagio era encerrarse la población dentro del recinto amurallado; el Arrabalejo era la zona más poblada de los arrabales extramuros y el concejo municipal estudiaba la forma de obligar a sus habitantes a abandonar las casas y a establecerse dentro de la ciudad; como hubo resistencia por parte de los vecinos se fue estudiando el modo de asegurar el aislamiento del Arrabalejo con el exterior, para lo cual se elevaron muros en los patios de las casas que alindaban con el campo, se cortaron calles que salían también al campo e incluso se cortaron las ramas de los árboles que estuviesen sobre las cercas, para evitar la entrada y salida de forasteros, mientras cuadrillas de labradores vigilaban noche y día alrededor de la ciudad" 27.

Tenemos escasas noticias sobre la zona a lo largo del S. XVIII y XIX, a excepción del material cartográfico que hemos comentado. Ya en el siglo $X X$, el solar sufre importantes agresiones como la construcción de la Escuela de Enfermería, un depósito de agua y el parque de Bomberos.

\section{LOS DATOS ARQUEOLÓGICOS}

A pesar de la destrucción del solar a lo largo de la centuria anterior se han podido extraer datos, en ocasiones muy escasos, que permiten hacer una lectura bastante amplia de la ocupación de esta zona y su relación con la dinámica urbanística de la ciudad.

\footnotetext{
24 Relación... 2001:225. Recogido del estudio realizado por D. Vicente Salvatierra Cuenca para la Carta de Riesgo de la ciudad de Jaén y al que agradecemos que nos permitiera su consulta. 
Los restos más antiguos (C/4) son estructuras de forma circular, excavadas en la matriz geológica, muy deterioradas y asociadas a materiales prehistóricos de difícil adscripción a un periodo determinado (Lámina 2); también se documentan materiales fabricados a mano en el sondeo A2 sobre la matriz geológica (UE227).

La presencia de la muralla romana en la calle Borja y su posible trayectoria alineada con la muralla islámica generaron expectativas alentadoras para intentar definir el límite oeste del municipio Flavio Aurgitano ${ }^{28}$. Para documentar este elemento estructural se planteó un transet que permitiera localizar indicios tanto de la muralla romana como de la islámica; los resultados son: en los niveles superiores un conjunto de materiales y estructuras del S.XIX (al parecer una segunda almazara) ${ }^{29}$, en el sector sur la base geológica aparece a un nivel bastante elevado y por último un conjunto de materiales con un elevado índice de rodamiento, concentrados en el sector nororiental del solar (sondeo C2 y Cl 19-20) con una cronología que abarca desde el siglo I al III, predominando los más tardíos; no hemos documentado ningún elemento que pudiera identificarse con alguno de los conjuntos defensivos.

Por su tipología se interpretan como posibles sepulturas tardorromanas o visigodas unos rebajes artificiales en la matriz geológica. En el sondeo A3 se documentan dos de estas estructuras en dirección Este-Oeste (UE. I I3-UE. I I5. Fig. 2); la primera de ellas presenta un muro de mampuesto de 0,50 $\mathrm{m}$ de ancho (UE. I I4), con una orientación similar, construido para crear un borde allí donde la roca presenta un desnivel; se genera de esta forma una fosa de unos 0,60 $\mathrm{m}$ de anchura, sin poder determinar su longitud. Probablemente a estas estructuras deben pertenecer unos restos óseos humanos localizados en un nivel de relleno (UE. II I) sobre la base geológica.
En el sondeo B4 documentamos tres estructuras de las mismas características y orientación (UE.66- I I 8 y 199), dos de ellas presentan sendos muros de mampuesto (UE. 65-I37), conformando el lateral de la fosa allí donde la roca no pudo ser excavada al presentar una cota más baja.

Será en época islámica cuando se produce la verdadera urbanización del solar. Como comentábamos más arriba, se conservan parte del lienzo y un torreón circular que fueron restaurados por D. Luis Berges; del estudio murario realizado en la primera fase, se ha podido comprobar que de la mayor parte del alzado que hoy vemos y que pertenece a la restauración realizada entre los años 1972-73, es la cara sur la que conserva parte de su alzado en la base del muro que estuvo originalmente enterrado en parte hasta que fue abierta la calle Molino Condesa y rebajada la cota de pavimentación.

Este lienzo presenta un quiebro hacia el norte, en dirección a la torre en " $\mathrm{D}$ " a la que hemos hecho referencia antes; en este tramo de muralla, que fue reutilizada como cimiento por los muros de una almazara, se localiza la cimentación de una puerta, que identificamos como la "Puerta del Aceituno (Sondeo A3UE208) que tradicionalmente se había ubicado en la cercana Plaza de Cambil (Fig. 2). A pesar de su escasa conservación, por los datos obtenidos parece probable que el cuerpo de la puerta se construyese en piedra en lugar de tapial, material con el que se levantó la muralla y que estuviese enlucida al igual que aquella. Hubo de sufrir problemas estructurales ya que se recalzó en época islámica (UE2I0). A intramuros aún se conservan restos de su pavimento.

Desde la puerta la muralla sigue en dirección norte hasta enlazar con la torre embutida en el actual muro de contención con la calle Millán de Priego. La torre se documenta en el

\footnotetext{
28 Corte C2 de la primera fase y C19 - 20 en la tercera fase.

29 Archivo Histórico Municipal. Cartografía del Ingeniero geógrafo Antonio Revenga.
} 
sondeo $\mathrm{A} 2$, su fábrica es de sillarejo regular bien labrado, y el interior macizo, se rellena con piedra ligada con mortero de cal; estructuralmente la torre presenta una forma en " $D$ ", formada por un rectángulo de $6 \times 4$ metros al que en su lado occidental se adosa un semicírculo de 3 metros de diámetro, la transición de la recta a la curva se resuelve con unos pequeños ángulos que sobresalen unos 0,10 metros de la superficie curva.

Desde la torre, la muralla sigue en dirección Este coincidiendo "a priori" con el muro de contención de la C/ Millán de Priego por lo que planteamos un sondeo (corte 16) en esta zona para comprobar esta posibilidad. Efectivamente parte de este muro se corresponde con la muralla aunque tan solo pudimos documentar 8 metros ya que con la construcción del parque de bomberos la seccionaron para levantar un muro de hormigón, según noticias orales ciego, por lo que el tramo externo puede corresponderse con la funda cristiana.

En la sección de la muralla podemos observar tres fases (Lámina 3; Fig. 5)

I. La muralla de tapial perteneciente a época almohade que conserva unos 1,60 m de altura y asienta directamente sobre la roca.

2. El forro de piedra realizado por el Condestable D. Miguel Lucas de Iranzo (I4621473) y que utiliza como cimiento el tapial del período anterior. De estos momentos se documenta el nivel de pavimentación (UE 16013-UE 16015).

3. Un nuevo encamisado posiblemente realizado en el siglo XVI para mantener el fielato. Según Soledad Lázaro, en 1573 se desmonta él recodo de la puerta, por lo que es probable que fuese en estas fechas cuando se produce el arreglo de todo. En estos momentos ya no se ve el cimiento de tapial y los niveles de uso se habían elevado considerablemente, asentándose el cimiento sobre la estratigrafía de épocas anteriores.

A partir de aquí, la muralla no se ha conservado en ningún punto del solar y no sabemos como se produjo su desaparición; es evi- dente que las construcciones del siglo anterior fueron muy agresivas (molino de aceite, parque de bomberos), no obstante es muy probable que estuviese muy deteriorada desde antiguo; concretamente en el C/ 19-20 donde se hizo un transet amplio para intentar localizar la muralla islámica y romana, no aparece ningún indicio de la misma.

Con respecto a la cronología de fundación de la muralla, hemos podido comprobar se construye en el S. XII, lo que viene a ratificar los datos obtenidos en otras intervenciones.

Por lo que se refiere a la organización interna del espacio, en primer lugar constatamos un tratamiento del terreno natural. En este sentido, las construcciones documentadas aparecen en dos niveles generados por aterrazamientos, método habitual utilizado en la ciudad desde época romana para construir en un terreno tan accidentado como la ladera del cerro Sta. Catalina.

La primera terraza se localiza en la zona sur del solar (Corte 17) donde detectamos una regularización del terreno natural previo a la construcción; en este sondeo, se ha localizado la cimentación de dos muros en ángulo de 75. : el primero de ellos tiene una anchura de 58 $\mathrm{cm}$ y parece que se adosa directamente a la muralla de tapial, sobre él montan los muros de la almazara; el segundo es más estrecho, unos $40 \mathrm{~cm}$ y se encuentra mucho más arrasado (Lámina 4). La cerámica recuperada de los niveles asociados a estas estructuras ofrece una cronología de finales del S. XII, inicios del XIII.

El segundo nivel de construcciones se localiza en los cortes 16 y 18 , muy próximos a la muralla.

En el corte 16 (Figs. 2 y 3), la primera fase islámica documentada corresponde a dos habitaciones conformadas por un muro principal en dirección Este-Oeste y otro perpendicular al mismo (con ángulo de 75\%) con dirección surnorte, fabricados en mampostería irregular, ambos están a cota de cimentación por lo que no se han documentado sus suelos de uso; 
relacionados con estos muros localizamos dos atarjeas, una principal con sentido Este-Oeste que discurre entre la casa y la muralla, y otra secundaria que atraviesa las habitaciones y va a desembocar a la anterior (Lámina 5).

La construcción de la muralla rompe los restos de una posible vivienda con muros de piedra unida con argamasa y suelo bastante compacto con cal. Por los materiales recuperados no hay indicios de una cronología anterior al S. XII por lo que pensamos nos estamos moviendo en un entorno cronológico bastante reducido.

En los puntos donde llegamos a la matriz geológica en este sondeo está bastante regularizada; idénticos resultados ofrece el corte 18, por lo que parece probable la existencia de un paso de ronda, bajo el cual se disponen las grandes atarjeas.

El corte 18 (Figs. 2-4) se dividió por cuestiones metodológicas en tres sectores: el I correspondía al antiguo transet $\mathrm{B} / 2-\mathrm{B} / 5$ de la campaña de 1999 y quedaba en la zona central; el sector 2 hacia el W y el sector 3 al Este.

- Sector I: en la primera campaña se localizó una calle en dirección sur-norte, que se identifica con la C/ Atienza que aparece en la planimetría de I887. Bajo el pavimento de la misma se localiza una gran canalización que desemboca en dos colaterales. En esta campaña fue excavado a nivel de limpieza y definición de las conducciones. Como posteriormente veremos, parece muy probable que el origen de esta calle fuese muy anterior, ya que los cimientos de viviendas islámicas reutilizadas en el S. XIX hacen fachada hacia este espacio y las canalizaciones, de claro origen islámico, discurren por un espacio público (Lámina 6-7).

- Sector 2: documentamos los restos de un edificio dedicado al filtrado, decantación y almacenaje del aceite. Los muros Norte y Sur se encuentran arrasados y hacia el W ha desaparecido completamente por las actuaciones de época contemporánea, no así el Este que hace fachada a la calle docu- mentada en el sector n. ${ }^{\circ}$ I (Lámina 8). La habitación estaba colmada por un nivel formado exclusivamente por yeserías; la instalación de este espacio se fecha en el S. XIV y se mantiene durante el $\mathrm{S}$. $\mathrm{XV}$, es el único caso que hemos detectado en la intervención de reutilización en época bajomedieval de estructuras preexistentes islámicas.

- Sector 3: la totalidad de los muros localizados que conforman al menos lo que pudieron ser dos habitaciones, se encuentran a nivel de cimentación. Todos ellos presentan un sistema constructivo similar: mampostería irregular ligada con argamasa de cal que ofrece una tonalidad amarillenta. La cronología de los mismos es islámica, las viviendas hacen fachada a la calle y fueron reutilizados en época contemporánea. Antes de la instalación de estas estructuras se recortó la roca hacia el norte, quedando dos planos topográficos: si en el superior se instalan las viviendas, en el segundo la matriz geológica aparece trabajada y alisada; como ya apuntábamos esta situación parece propicia para pensar en la existencia de un paso de ronda entre las viviendas y la muralla (Lámina 10).

Entre esta fase y la siguiente se documenta la transición entre el último periodo de ocupación islámica y los inicios del medievo cristiano.

Durante el S. XV, se lleva a cabo un refortificación de la cerca islámica y una nueva restauración de la torre documentada en la UE33. Esta fase constructiva se realiza a instancias del Condestable Iranzo y consiste en recortar la muralla de tapial (UE I70 y 17I) para forrarla con una camisa de piedra extramuros (UE I 42) e intramuros (UEI57). Se ha podido documentar igualmente la presencia de los suelos de tránsito asociados a las reformas de este momento.

De época moderna $(\mathrm{S} . \mathrm{XVI})$ se construye un encamisado de piedra adosado a la fábrica preexistente, únicamente intramuros. Esta nueva fortificación debemos entenderla con un carácter netamente fiscal y no tanto defensivo, ya que uno de los tres últimos fielatos en uso hasta épocas recientes fue el de la Puerta del Aceituno. 
Por último a época contemporánea corresponden los restos de la almazara que afectó a la torre y de la que se conservan numerosos restos en todo el sector, así como el pavimento de la que puede ser la C/ Atienza, que aparece en un plano de 1887 y un buen número de estructuras pertenecientes a viviendas.

\section{CONCLUSIONES}

La secuencia cronológica del solar es muy amplia, con algunos hiatus que parecen estar en consonancia con la trayectoria histórica de la zona.

De época prehistórica, las estructuras subterráneas asociadas a materiales a mano así como los materiales rellenando los desniveles de la roca parece responder a finales de la Edad del Bronce, momento en que la finalización del poblamiento concentrado calcolítico (Marroquíes Bajos), dio lugar a la creación de un nuevo modelo de poblamiento, caracterizado por núcleos reducidos y aislados que se dispersan en una superficie considerable al Norte del Cerro de Sta. Catalina ${ }^{30}$. En este sentido, se han documentado elementos de este periodo en intervenciones realizadas en un entorno más o menos próximo como la calle Stma. Trinidad ${ }^{31}$, Llana de S. Juan ${ }^{32}$, Juanito el Practicante ${ }^{33}$ y Muralla Norte ${ }^{34}$, así como en zonas bastante más alejadas como en la calle Vicente Montuno ${ }^{35}$ n. ${ }^{\circ} 21$ y 23.

No parece descabellado pensar, que la presencia de este pequeño núcleo (tomando todas las reservas) esté claramente relacionado con la cercanía del cauce del arroyo de la Magdalena localizado en el sondeo C3.
No se ha documentado ningún indicio de niveles ibéricos en el solar, lo que en principio parece estar en consonancia con los datos que se tienen hasta el momento sobre este periodo en el entorno inmediato, ya que parece concentrarse en la zona del cerro Sta. Catalina, donde mantienen su mayor grado de habitabilidad en la fase más antigua. Desde mediados del S.V a mediados del IV a. C., se produce un abandono del asentamiento que vuelve a ocuparse en el S. III a. C., momento en que se reorganiza el asentamiento y se construyen defensas de carácter ciclópeo (torres y lienzos) que con posterioridad serán nuevamente utilizados en época medieval como cimientos de la cerca islámica. A partir del siglo II y I a. C., el poblamiento se reagrupa en las zonas de meseta, arbitrándose un recinto de reducidas proporciones al tiempo que se produce un traslado de la población hacia zonas más bajas ${ }^{36}$.

En época romana, el solar se encuentra en los límites de la ciudad; la hipótesis de partida era que la muralla romana se encontraba paralela al actual trazado de la muralla islámica, no obstante, la inexistencia de cualquier indicio de ambos sistemas defensivos a excepción de los materiales recogidos en el corte 19/20 nos introduce en el terreno de las hipótesis; pensamos que existen dos opciones:

I. Pudo ser destruida al igual que la islámica y mantener un trazado más o menos paralelo, con lo cual englobaría a las grandes construcciones como las termas o el acueducto. Esta hipótesis podría estar avalada por la propia dejadez en el mantenimiento de la muralla casi desde su construcción siendo un elemento con un carácter más

\footnotetext{
30 Serrano, J.L: Memoria de Licenciatura. También Zafra et alii, 1997.

31 Zafra, 1995.

32 Serrano y Esteban, 1997.

33 Serrano, 1995.

34 Castillo y Cano, 1993.

35 Jiménez, 1992.

36 A estos momentos pertenecen las estructuras y materiales documentados en la zona existente entre la C/ Baños de la Audiencia y Espartería.
} 
administrativo que militar ${ }^{37}$; su conservación en un punto concreto como la C/ Borja pudo deberse a múltiples causas que por el momento no podemos definir. Otro factor a la hora de explicar su desaparición es el importante esfuerzo constructivo y de aterrazamiento realizado en el siglo XII como veremos más adelante.

2. La segunda opción es que girase mucho antes en dirección sur, ya que realmente no se ha detectado en el solar ningún indicador de su presencia ni de cualquier otro tipo de ocupación, a excepción de los materiales ya mencionados.

En cualquier caso, pensamos que no fue una zona urbanizada y aunque no en su totalidad, pudo formar parte de los jardines de cierta extensión junto a las termas que mencionan las inscripciones localizadas.

Ya comentábamos en el epígrafe anterior que en época visigoda, nuestra zona de estudio estaba deshabitada; a las noticias de la presencia de inhumaciones aisladas en los alrededores, hay que unir en este caso la presencia de sepulturas que por su tipología son similares a las localizadas en Marroquíes Bajos y que según todos los indicios pueden adscribirse a este período. Los hallazgos de restos arquitectónicos en las inmediaciones, hacen pensar en la existencia de un edificio religioso en el entorno, lo que daría un mayor sentido a las sepulturas y ratificaría el carácter externo con respecto al perímetro urbano del solar. Por el momento en la ciudad se han localizado indicios de dos construcciones de este tipo que de forma habitual se ubican en las afueras; una de ellas en la calle Las Huertas ${ }^{38}$, y otro en la zona de Marroquíes Bajos donde junto a los restos arquitectónicos reutilizados en cons- trucciones islámicas se ha documentado una importante necrópolis ${ }^{39}$.

La condición de zona despoblada se mantiene durante los períodos emiral y califal, de los que no hemos localizado ningún material a pesar de la cercanía del centro político-religioso ubicado en el entorno de la Magdalena a raíz de su nombramiento como capital de la Cora de Yayyan por Abd-al-Rahman II (822855), decisión que se refuerza con la construcción de la mezquita aljama en el solar donde actualmente se levanta la Iglesia de la Magdalena y de la que aún se conservan su alminar y algunos restos de arquerías en su patio; junto a la misma en el solar del actual Convento de Sta. Úrsula se encontraban las antiguas termas romanas que han sido identificadas con el baño islámico mencionado en las fuentes como Baño del Toro; frente a la mezquita el raudal de la Magdalena, y muy cercano a ella la Casa del Cadiato, aunque las referencias en este caso son muy endebles.

Al margen de los edificios públicos, los datos sobre las viviendas de época emiral y califal dentro del actual casco histórico son prácticamente inexistentes, $y$ al parecer la ciudad no debía superar los límites de la antigua urbe romana ${ }^{40}$; no obstante las intervenciones que se vienen realizando en la zona de Marroquíes Bajos desde el año 1995 han sacado a la luz la existencia de un amplio núcleo de origen emiral, consolidado en el periodo califal (20 h.), con clara tendencia agropecuaria, que permiten esbozar un nuevo modelo de ciudad muy distinto al tipo de ciudad andalusí, donde los estamentos de poder se asientan en la antigua ciudad romana, rodeado de "arrabales", en nuestro caso con una extensión mayor que el propio núcleo amurallado, con una clara especialización funcional ${ }^{4 !}$.

\footnotetext{
37 Serrano, 1999.

38 Zafra, 1993., Serrano, 1999.

39 Pérez y Serrano; Serrano y Pérez; Martínez y Manzano.

40 La intensa actividad constructiva a partir del siglo XIl y posteriormente en época moderna pudo ser una de las causas de la desaparición de los niveles más antiguos.

4I Salvatierra et alii, 1998.
} 
Aunque en la muralla norte se ha conseguido detectar parte del lienzo amurallado levantado en época emiral y algunas reestructuraciones y elementos de época califal, en ninguna de las intervenciones realizadas en el casco histórico se han documentado indicios de las defensas que envolverían el recinto de la ciudad en estos periodos; en este caso parece adecuado pensar que se mantendrían las murallas romanas y muy probable que los edificios públicos se instalasen en el interior de las mismas.

Con el hundimiento del califato y la inestabilidad que se genera ${ }^{42}$, se detecta un completo abandono del núcleo no amurallado cuya consecuencia inmediata es una afluencia importante de población hacia el interior del recinto protegido que, inevitablemente conlleva a un crecimiento progresivo de la ciudad hasta su definitiva macización en el siglo XIl; es más que probable que nuestra área de estudio se mantuviese deshabitada a lo largo del siglo XI ${ }^{43}$, ya que la tendencia de crecimiento en estos momentos se dirige hacia el Este, a nuestro juicio planificada desde los estamentos superiores, con la construcción de nuevos edificios públicos como el "Baño del Naranjo" y una mezquita junto al mismo de la que se localizó su alminar ${ }^{44}$.

Es en el siglo XII cuando se produce la verdadera urbanización de esta zona gracias a la ampliación del recinto amurallado que se construye en estas fechas.

A excepción del lienzo y torre restaurado por D. Luis Berges, el resto del tramo aparece muy afectado por las construcciones pos- teriores, parte del mismo (con las reformas posteriores) sirve actualmente como muro de contención con la calle Millán de Priego, al menos en algunos puntos, en otros atravesaría el solar en dirección a la medianera de las casas de la C/ Millán de Priego con la C/ Borja y Fernando IV; la desaparición de la muralla se debe fundamentalmente a las obras realizadas durante el siglo XX, no obstante tenemos noticias de que se encontraba en mal estado desde el S. XVII, así en I 684 un grupo de vecinos pidió que se demoliese parte de la muralla del arrabalejo porque amenazaba ruina y era un peligro para las viviendas próximas ${ }^{45}$.

Hasta la intervención actual, la Puerta del Aceituno se ubicaba en la cercana plaza de Cambil; según Ma Soledad Lázaro, "el trazado en recodo de la misma era un hecho hasta el siglo $\mathrm{XVI}$, lo que crea muchos inconvenientes en esta centuria por lo que existen claros intentos de suprimir su recodo", lo que al parecer se consigue en 1573, siendo la única puerta modificada.

Tanto la puerta de Sta. Ma como la del Aceituno contaban con barbacana, en el S. XVI se afirma que el adarve o barbacana contaba con saeteras y una anchura de "siete a ocho pies y obra de una lanza de alto" 46 que "los antiguos avian hecho para guarda y amparo de la dicha puerta ${ }^{47}$ y que estavan ansi todas las puertas de la dicha cibdad" 48 .

La puerta se alzaba entre dos torres cuya planta, según Pi Margall, era cuadrada. Pi Margall señalaba aberturas circulares en ellas las cuales debieron serle practicadas en época

\footnotetext{
42 Con las continuas revueltas, se detecta un abandono total de la zona de Marroquíes Bajos; este abandono se produce de forma más o menos ordenada en algunos casos y violenta en otros a juzgar por los ajuares documentados en algunas viviendas y los niveles de incendio.

$43 \mathrm{Se}$ han documentado algunas estructuras rotas por la muralla aunque sin materiales que nos hagan pensar en un siglo $\mathrm{Xl}$; no obstante el intenso nivel constructivo de época almohade pudo hacer desaparecer estos indicios, por tanto si hubo algún tipo de ocupación pudo ser muy concreta.

44 Pérez y Alcázar, 1993.

45 A.M.J, A.C., cab. De 18 de septiembre de 1684. Citado por CORONAS TEJADA, 1994, p. 10.

46 A.M.J.A.C.A.C. 1573, sept. 2.

47 Idem.

48 Idem.
} 
moderna con el fin de dar luz a sus cámaras inferiores y superiores también arrendadas por el Cabildo Municipal a particulares ${ }^{49}$. Ante ella se coloca una barbacana y muy posiblemente una cava o foso ya que se menciona un puente ${ }^{50}$ que aún existía en el $\mathrm{S}$. XVIII, aunque en un estado lamentable:

"En relación al puente que existía a la salida de la Puerta del Aceituno, por donde discurrían las aguas sobrantes del raudal de la Magdalena, su estado estaba tan gravemente deteriorado 'que con gran trabajo y cuidado se trajina por él, por no tener pretiles y estar desguazados los lados de los cimientos, por cuya causa se han desgraciado en él diferentes carros y cabalgaduras, habiendo caido en él diferentes carros y cabalgaduras, habiendo caido de lo alto del dicho puente al arroyo'. Para el arreglo de este puente, eran precisas veinte varas de pretil por cada lado, veinte varas de empedrado y un caño de piedra para desaguadero de las aguas que bajaban de la puerta.

En cuanto a la Puerta de Martos, manifestaron que no convenía cortar los arcos de la misma ya que eran estribo de las torres de la puerta, pero que era muy conveniente rebajar las torres y recalzar las puertas.

El coste total de las obras a realizar suponía 60 reales, precio bajo teniendo en cuenta que se utilizaría la gran cantidad de piedras procedentes del derribo de la parte alta de las torres. La ciudad acordó que así se hiciera, comisionando los caballeros veinticuatro para ello, y con el encargo de repartir esta cantidad entre las personas "que legitimamente deban contribuir respecto a ser de su beneficio el que el puente esté transitable y trajinable" 5 !.
No ha habido posibilidad de encontrar indicios de este puente, aunque parece muy probable que se encontrase en el interior del solar actual, ya que el algibe realizado para el parque de bomberos ha destrozado las posibilidades de conocer el acceso a la puerta. Por lo que respecta a la cava, se ha documentado una importante "zanja" (corte I5) (Fig. 7) realizada en la matriz geológica y amortizada con materiales de época moderna (S. $\mathrm{XVII-XVIII);} \mathrm{este} \mathrm{rebaje} \mathrm{no} \mathrm{llega} \mathrm{hasta} \mathrm{la} \mathrm{torre}$ circular donde se arbitra lo que parece ser una zona de paso de aproximadamente tres metros (Lámina II). No hemos podido seguir la trayectoria de esta posible cava por la misma razón antes argumentada.

En 1794 la puerta aún estaba en pie ya que Martínez de Mazas la menciona, no así Madoz, por lo que cabe suponer habría sido demolida entre esa fecha y 1844. En este entorno cronológico, hemos localizado una noticia en las actas capitulares $^{52}$ de 1838 en la que se advierte del peligro de hundimiento en el "Arco del Arrabalejo"; se propone su demolición y que los materiales se depositen en el Campillejo de Cambil. A priori, no sabemos si se trata de la Puerta del Aceituno o de algún portillo del que no tenemos ninguna referencia, no obstante la cercanía del Campillejo de Cambil hace probable que se refiera a esta estructura.

En el proceso de ocupación de la zona en estos momentos hemos documentado dos fases que se deducen por posición estratigráfica o por la invasión de los espacios de ronda adosándose a la muralla, ya que el conjunto de materiales ${ }^{53}$ asociados a todas las estructuras presenta un entorno cronológico no superior a 75 años.

\footnotetext{
49 Lázaro, 1978, pág. 44.

50 A.M.J.A.C. 1586.

51 A.H.M.J. A.C-19 de enero de 1705. Casañas Llagostera, P: Revista Paisaje n 3।, pp. I I0-1। I.

52 AMJ., A.C. 1838, marzo 5, 55 r ${ }^{\circ}$.

53 El conjunto cerámico está representado por estampillados (Lámina 12, I y 2), esgrafiados (Lámina 12, 3 y 7), cuerdas secas parciales (Lámina 12, 8 y 10) y totales (Lámina 12, II). Las formas también indican un período de mediados del S. XII, mediados del XIII, con soleros muy prominentes, candiles de piqueras muy desarrolladas (Lámina |3, I y 2) o candiles de pie alto (Lámina |3, 3).
} 
En la primera de ellas se detecta una clara planificación y presenta un marcado carácter urbano; en primer lugar, la complicada orografía hacia necesario una preparación previa del terreno que les permitiese la construcción de tal forma que se organizan al menos tres terrazas ${ }^{54}$, en la más baja se instala la muralla con un paso de ronda delimitado por la pared externa de las viviendas situadas a un nivel superior; la presencia de una red jerarquizada de canalizaciones con salidas hacia las viviendas, y el que estas discurren por un vial hacen evidente las dos premisas expuestas más arriba.

La segunda fase se documenta en la primera terraza y está muy deteriorada, no obstante, el hecho de adosarse físicamente a la muralla parece indicar un momento muy tardío en el que se produce una auténtica macización de la ciudad, hecho que se constató ampliamente en un solar de similares características ${ }^{55}$ y que parece común a gran parte de las ciudades islámicas en estas fechas.

Otro punto interesante a tratar de este periodo es el del agua, tanto por la presencia de manantiales de gran envergadura como por el importante esfuerzo de encauzamiento y canalización de los mismos.

Concretamente en el sondeo $\mathrm{C} 3^{56}$ se ha documentado la margen izquierda del arroyo de la Magdalena que discurría por el solar con una dirección aproximada suroeste-noreste siguiendo el descenso natural del terreno hacia el exterior de la ciudad ${ }^{57}$. Probablemente por la zona discurría otro cauce procedente del arroyo de la Magdalena que desembocaría en la zona NW del solar, siendo posiblemente el causante del deterioro del puente de acceso a la puerta ${ }^{58}$, o el hundimiento en 1693, de una torre que había entre las Puertas de Martos y del Aceituno por la humedad provocada por el caño de agua que desde la Magdalena iba a regar las huertas extramuros ${ }^{59}$.

La importancia del raudal de agua de la Magdalena es un hecho del que se hacen eco todas las fuentes escritas desde época islámica; desde la arqueología no solo se ha confirmado esta situación, sino también el gran esfuerzo de canalizar y controlar esta agua ${ }^{60}$, como se hace patente en esta excavación.

Ejemplos muy cercanos sobre este tema y de esta fecha tenemos varios; en la calle Escalerillas ${ }^{61}$, se localizaron unas canalizaciones pertenecientes al S. XIl; en el edificio Veredas se documenta un arroyo con materiales de arrastre desde la Edad del Bronce hasta el periodo romano y que se encauza en estas fechas; en el Palacio de los Uribe ${ }^{62}$ se localiza una mina de agua con entrada adintelada y cubierta a dos aguas construida con losas que en el punto más alto tienen I,80 m y una anchura aproximada de $0,70 \mathrm{~m}$. Después de un tramo inicial de unos $20 \mathrm{~m}$ aproximadamente, la estructura presenta una bifurcación en dirección EsteOeste. Por similitudes con construcciones de las mismas características, documentadas en la zona de la Imora en Jaén y en Córdoba en Madinat Al-Zahra, podríamos decir que se trata del alcantarillado construido posiblemente entre finales del siglo XI-XII.

\footnotetext{
54 Los movimientos de tierra en el siglo pasado han modificado enormemente la topografía de la zona.

55 Castillo et alii, 1991.

56 Primera fase de intervención.

57 Salvatierra, 1995.

58 Idem cit. 41

59 A.M.J., AC., cab de 10 de Julio de 1693. Coronas Tejada, p. II.

60 Salvatierra et alii, 1998.

61 Marín, 1991.

62 Cano, 1994.
} 
Tras la conquista cristiana, se produce la reutilización de algunas estructuras de vivienda; documentamos una habitación con un suelo de cal impermeable cuyo uso podría estar relacionado con el procesado del aceite: desde un depósito superior se da salida a un espacio que funcionaría como paso intermedio de filtrado antes de su posterior decantación en un depósito más profundo. Esta habitación se encontraba arrasada por niveles contemporáneos, por lo que no podemos precisar la existencia de más depósitos ni las dimensiones exactas del mismo. Construido directamente sobre las cimentaciones islámicas anteriores, el molino tuvo un uso prolongado en el tiempo como lo demuestran las sucesivas reparaciones del pavimento.

El topónimo de Puerta del Aceituno es posible que guarde relación con la existencia de este pequeño molino.

Por lo que respecta a las estructuras defensivas, a lo largo del período bajomedieval hay una preocupación constante por el estado de las murallas que se reparan continuamente.

Será el Condestable D. Miguel Lucas de Iranzo quien hace los mayores esfuerzos tanto desde el punto de vista urbanístico como de reconstrucción y mantenimiento del lienzo defensivo. Según las fuentes, en el tramo de muralla comprendido entre las puertas de Martos y el Aceituno, ambas inclusive, el Condestable hizo levantar inicialmente cinco molinos, que fueron seguidos de otros hasta llegar a treinta, para abastecer de harina a la ciudad ${ }^{63} \mathrm{y}$ :

"...para guarda y defensa de los dichos molinos, mandó fazer desde las Peñuelas, baxo de la Puerta de Martos, fasta la cava que llega al adarve, una cava; do mando poner muchos mandeletes. E iva por el camino que va debaxo de las dichas peñuelas, fasta la puerta del Azeitu- no, otra cava bien fuerte. La qual, asi mesmo, mandó fortificar con muchos mandeletes y tapiales..." (Relación...2001:225).

Como ya hemos comentado de esta época data una de las fundas de mampostería de la muralla y un suelo de ocupación que amortiza algunas de las estructuras islámicas.

El recorte antrópico frente a la puerta pueda identificarse con la cava descrita en la crónica del condestable que junto con el muro de dirección E-W (UE I 5003) que abre un vano junto a la torre circular (Figura 7), supondría un refuerzo defensivo importante al disponer una zona de entrada relativamente pequeña (3 metros) para acceder al espacio triangular que se conforma por la estructura de la Puerta del Aceituno.

Por último, la única construcción de relevancia realizada en el entorno antes del siglo $\mathrm{XVI}$, fue el hospital de la Misericordia, enclavado en la collación de S. Miguel y fundado antes de 1499. En 1619 el Cabildo civil, que nombraba anualmente como patrón de esta fundación a un Caballero Veinticuatro de la ciudad, decidió fusionarlo con otro más pequeño, fuera de la puerta de Martos, y entregarlo a la Orden de S. Juan de Dios ${ }^{64}$.

De la etapa moderna no hemos constatado ningún nivel de habitación, a pesar de la expansión de arrabales como el de S. IIdefonso o el de las Monjas a lo largo del siglo XVI, esta zona es la que presenta un menor incremento de población siendo la zona ocupada en su mayor parte por huertas; el declive que sufre la ciudad a lo largo del siglo XVII con un descenso importante de población ${ }^{65}$ no mejora el panorama.

Las murallas se arreglan en el siglo XVI con una segunda funda de mampostería y al pare-

\footnotetext{
63 Salvatierra et alii. 2002. "La carta de riesgo en el ámbito urbano: Jaén". Trabajo que se viene realizando en el marco del Proyecto Urban. Inédito. Agradecemos a los autores la consulta de este texto.

64 Ulierte, 1990.

65 A lo largo de este siglo se producen al menos tres epidemias de peste, varios periodos de sequía y plagas de langosta que diezman la población.
} 
cer en estos momentos también se remodeló la puerta del Aceituno eliminando él recodo; los esfuerzos por mantener el conjunto no tienen un interés tan defensivo como administrativo y fiscal, ya que ésta es una de las puertas que mantienen fielato. A partir de estos momentos, las noticias son de un constante deterioro de las murallas y de la puerta, aunque aún en el siglo XVII se cierran, como medida sanitaria para evitar la llegada de gentes contagiadas por la peste ${ }^{66}$.

Es en el S. XIX cuando se produce una verdadera urbanización de esta zona intramuros. En todos los cortes abiertos se han documentado evidencias de esta fase, destacando el establecimiento de una almazara en el extremo occidental del solar, que supondría un recrecimiento del sector occidental del mismo.

Será ya en el S. XX, fundamentalmente a partir de los años 50 cuando se produce una auténtica renovación del viario con la apertura de la C/ Molino Condesa y la construcción de la Escuela de Enfermeras. Por último la instalación del Parque de Bomberos será la actuación más agresiva.

\section{BIBLIOGRAFÍA}

AGUIRRE SÁDABA, F.J:: 1982. El Jaén islámico, En Historia de Jaén. Jaén, Pp. 159-200.

AGUIRRE SÁDABA, F.J. y SALVATIERRA CUENCA, V.: 1989. Cuando Jaén era Yayyan, en Jaén Vol. II Historia. Granada, pp. 453-490.

CANO CARRILLO, J.: 1994. Intervención arqueológica de urgencia en la casa de Los Uribes, Jaén. Archivo de la Delegación de Cultura.

CASTILLO ARMENTEROS, J.C.: 1998. La Campiña de Jaén en época Emiral (s. VIII-X). Jaén, Universidad de Jaén, colección Martínez de Mazas. Serie Monografías de Arqueología Histórica.

CASTILLO, J.C., MARIN, M.M.: 1998. Excavaciones de apoyo a la restauración en el Castillo de Santa Catalina de Jaén. A.A.A. III. 1993. Sevilla.
CASTILLO ARMENTEROS, J.C. y CASTILLO ARMENTEROS, J.L.: 1991. Excavación arqueológica de urgencia en la Iglesia de San Juan (Jaén). AAA, III 1989. Sevilla; pp. 292-303.

CASTILLO, J.L.; PEREZ, M.C.; MARIN, M.M.; ZAFRA, J.: 1995. Intervención arqueológica de urgencia en el solar sito entre las calles Millán de Priego, Hornos Franco, Rey Don Pedro y San Andrés de Jaén. A.A.A.II. 1992. Pág.396406. Sevilla.

CASTILLO, J.L;; CANO, J.: 1993. Diagnosis arqueológica de la Muralla Norte de Jaén. Archivo de la Delegación de Cultura en Jaén.

CAZABAN, A: 19|4. Jaén, Monumento romano. Don Lope de Sosa II. Jaén, pp 83-84.

CAZABAN, A: 1915. Una inscripción romana. Don Lope de Sosa. VOL. III. Jaén, pp. 67.

CAZABAN, A: 1915. Jaén urbanizado por los romanos. Don Lope de Sosa. VOL. III. Jaén, pp. 42.

CAZABAN, A: 1918. El bosque romano de Jaén. Notas e ilustraciones a un texto del Deán Mazas. En Don Lope de Sosa. Jaén. pp. 209-21.

CAZABAN, A.: 1919. En el "Huerto de Cárdenas" de Jaén. Un capitel visigótico. Don Lope de Sosa. N. 83. Vol.VII. Jaén; pp 34I-343.

CAZABAN, A: 1920. Lápidas sepulcrales en Jaén. En Don Lope de Sosa. Jaén; pp. 89-91.

CAZABAN, A: 1923. Hallazgo de un ara en la Puerta de Aceituno. En Don Lope de Sosa. Vol. XI. Jaén; pp. I88189.

CAZABAN, A: 1929. Alrededores de la Magdalena. En Don Lope de Sosa. Jaén; pp. 279.

CORONAS TEJADA, L.:1994. Jaén siglo XVII. I.E.G. Diputación de Jaén.

ESLAVA, J.: 1969. Importantes hallazgos arqueológicos en el Manantial de la Magdalena. Diario IDEAL, 30-8-1969. Jaén.

GABINETE PEDAGÓGICO DE BELLAS ARTES: 1987. Evolución urbana de la ciudad de Jaén. Jaén.

GALERA ANDREU, P. et alii: 1985. Catálogo Monumental de la ciudad de Jaén y su término. Jaén.

GÓMEZ DE TORO, M.E. y MOYA GARCÍA, S.: 1992. Informe sobre la actuación de urgencia realizada en el solar n. 3 de la C/ S. Miguel (Jaén). Archivo de la Delegación Provincial de Cultura.

LÁZARO, M.S.: 1978. Desarrollo histórico del casco urbano de Jaén hasta 1600. Jaén.

66 Coronas, 1994. P. 103. 
LÁZARO DAMAS, S.: 1987. Las Fuentes de Jaén. Jaén.

LLORENTE, M.: 1997. Intervención arqueológica de urgencia en el Conjunto Histórico de Jaén, calle Empedrada de La Magdalena. Archivo de la Delegación de Cultura en Jaén.

MARIN, M.M.; CASTILLO,J.C.: 1998. Excavación arqueológica de urgencia en calle Escalerillas n. ${ }^{\circ}$ de Jaén. A.A.A.III. 1993. Sevilla.

PEREZ MARTINEZ, M.C:: 1992. Intervención arqueológica de urgencia en Plaza Sto. Domingo n. ${ }^{\circ} 4$ de Jaén. Archivo de la Delegación de Cultura en Jaén.

PEREZ MARTINEZ, M.C:: 1992. Intervención arqueológica de urgencia en la calle Herrerías n. ${ }^{\circ} 5$ de Jaén. Archivo de la Delegación de Cultura en Jaén.

PEREZ MARTINEZ, M.C:: 1995. Intervención arqueológica de urgencia en la calle Millán de Priego n. 29 de Jaén. Archivo de la delegación de Cultura en Jaén.

PEREZ, M.C.; ESTEBAN, A.: 1992. Intervención arqueológica de urgencia en la calle Magdalena Baja n. ${ }^{\circ} 4$ - 6 de Jaén.A.A.A.III. 1992. Pág.392-395. Sevilla.

PÉREZ, M.C., JIMENEZ, Y., CANO, J.: 1995 Apuntes para el urbanismo musulmán de Jaén. El alminar en la intervención de C/ Martínez Molina - Los Caños. En Arqueología y Territorio Medieval 2, Granada, pp. II5-129.

PÉREZ, M.C., ALCÁZAR HERNÁNDEZ, E.Ma.: 1993: Aproximación al urbanismo de Jaén en el S. XI. En El Baño Árabe del Naranjo y la formación del edificio los Caños. Jaén

SALVATIERRA, V.: 1993. Jaén en los siglos XIII y XIV. La formación de la ciudad cristiana. En Revista del Centro de Estudios Históricos de Granada y su Reino, n. ${ }^{\circ} 7$, segunda época, Granada, pp. 147-167.

SALVATIERRA, V:: 1994. Arqueología Urbana: investigación e intervención, Patrimonio y Ciudad. Reflexión sobre centros históricos. Sevilla pp. 7|-76.

SALVATIERRA, V. y ALCÁZAR, E.: 1996. La distribución del agua en Jaén durante el período islámico. En Formas de Habitar e Alimentaçao na Idade Média. Mértola.

SALVATIERRA, V., PÉREZ, M.C., CASTILLO , J.L., ALCÁZAR, E. y CANO, J.: 1993. Formación y evolución de una ciudad islámica: Jaén. IV Congreso de Arqueología Medieval Española. Alicante, pp. 87-92.
SALVATIERRA, V., SERRANO, J.L. PÉREZ, M.C.1998. La formación de la ciudad en Al-Andalus. Elementos para una nueva propuesta. Genèse de la ville islamique en al-Andalus et au Maghreb occidental. Casa de Velázquez. C.S.I.C, Madrid, 1998, p. 185 - 206.

SERRANO, J.L. y CASTILLO, J.L.: I992. Excavación arqueológica de urgencia en el solar sito en la calle Magdalena Baja número I 5 de Jaén. AAA III 1990. Sevilla pp. 260264.

SERRANO, J.L.; PEREZ, M.C.: 1992. Excavación Arqueológica de Urgencia en la calle Martínez Molina N. ${ }^{\circ} 72$ de Jaén. AAA III 1990. Sevilla. pp. 306-308

SERRANO PEÑA, J.L:: 1995. Intervención arqueológica de urgencia en la calle Juanito el Practicante de Jaén. Archivo de la Delegación de Cultura en Jaén.

SERRANO, J.L.; ESTEBAN, A.: 1997. Intervención arqueológica de urgencia en el solar de calle Llana de San Juan esquina Santísima Trinidad de Jaén. AAA III 1994. Sevilla.

SERRANO, J.L.; ZAFRA, J.: 1997. Intervención Arqueológica de Urgencia en el solar de la calle Santo Domingo n. ${ }^{\circ}$ I de Jaén. En Anuario Arqueológico de Andalucía de 1993. III Actividades de Urgencia, pp.350-352.

SERRANO PEÑA, J.L: Aurgi: Estudio del Municipio romano desde la arqueológica urbana de Jaén 1985 - 1995. Memoria de licenciatura, 1999, inédito.

ULIERTE, Ma Luz de: 1990. Jaén. La ciudad y su historia. Granada.

V.V.A.A.: 1993. El Baño árabe del Naranjo y la formación del edificio Los Caños. Granada.

ZAFRA SÁNCHEZ, J.: 1992. Intervención arqueológica de urgencia en el solar de la Plaza Cambil n. ${ }^{\circ} 2$ de Jaén. Archivo de la Delegación de Cultura en Jaén.

ZAFRA SÁNCHEZ, J.: 1992. Intervención arqueológica de urgencia en el solar de la calle Borja n. ${ }^{\circ} 6$ de Jaén. Archivo de la Delegación de Cultura en Jaén.

ZAFRA, J.; CANO, J.: 1994. Excavación arqueológica de urgencia en el solar de la calle Las Huertas n. ${ }^{\circ}$ 5,7,9 de Jaén. Archivo de la Delegación de Cultura en Jaén.

ZAFRA, N; HORNOS, F; CASTRO, M; (1997): "Una macroaldea en el origen del modo de vida campesino: Marroquíes Bajos (Jaén) c. 2500 - 2000 cal. A.N.E. En Trabajos de Prehistoria, vol. 56, n. ${ }^{\circ}$. 


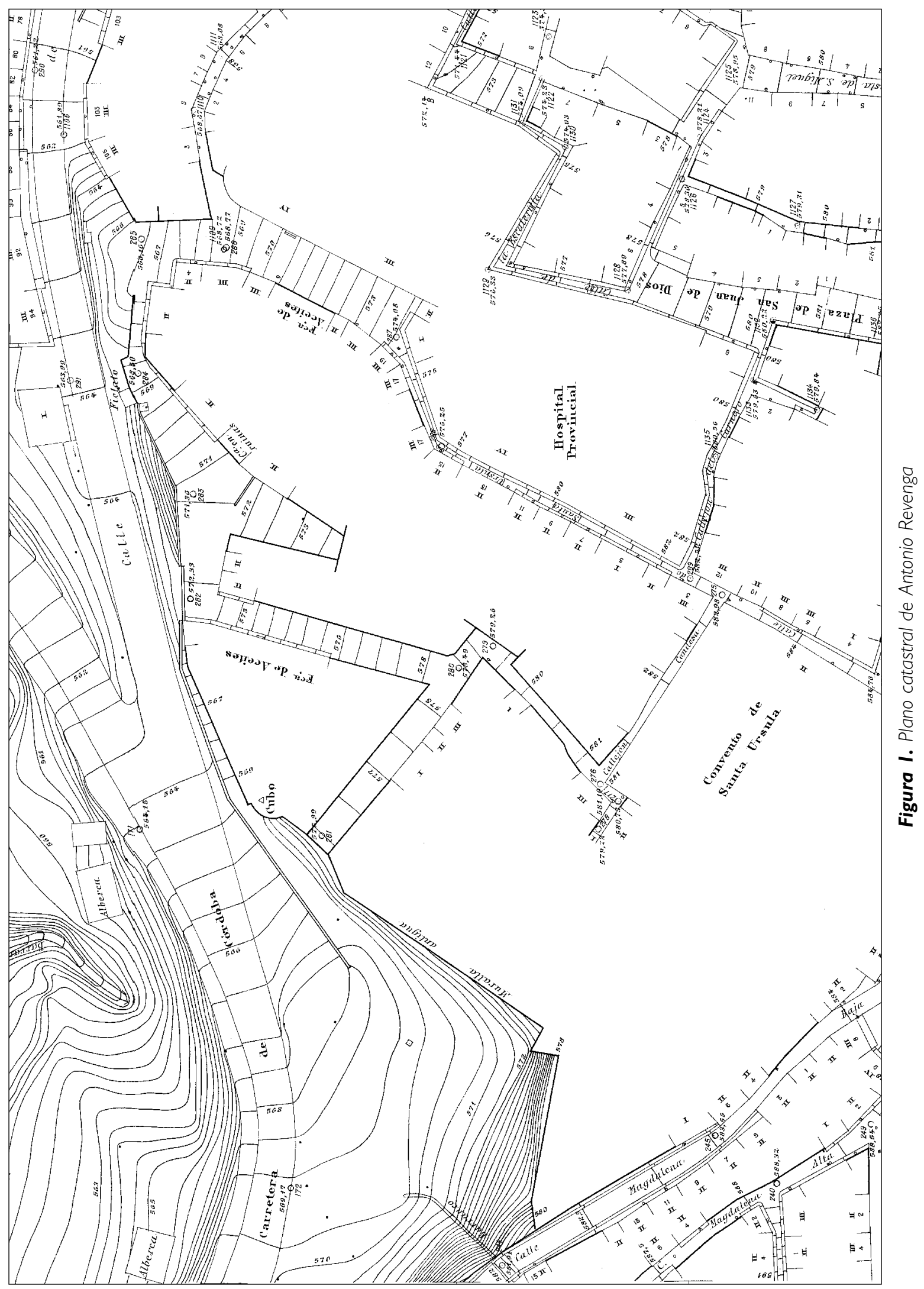




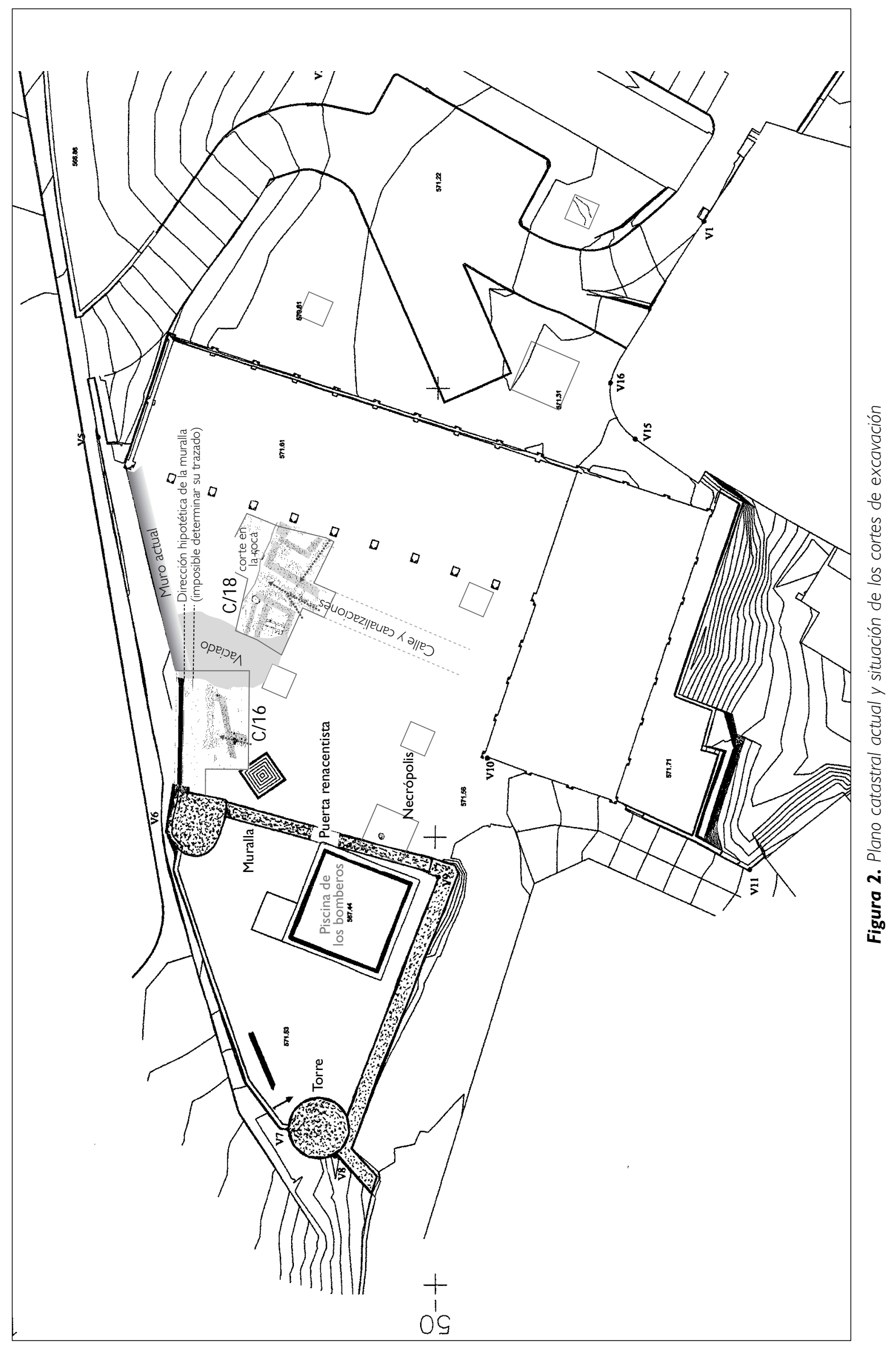




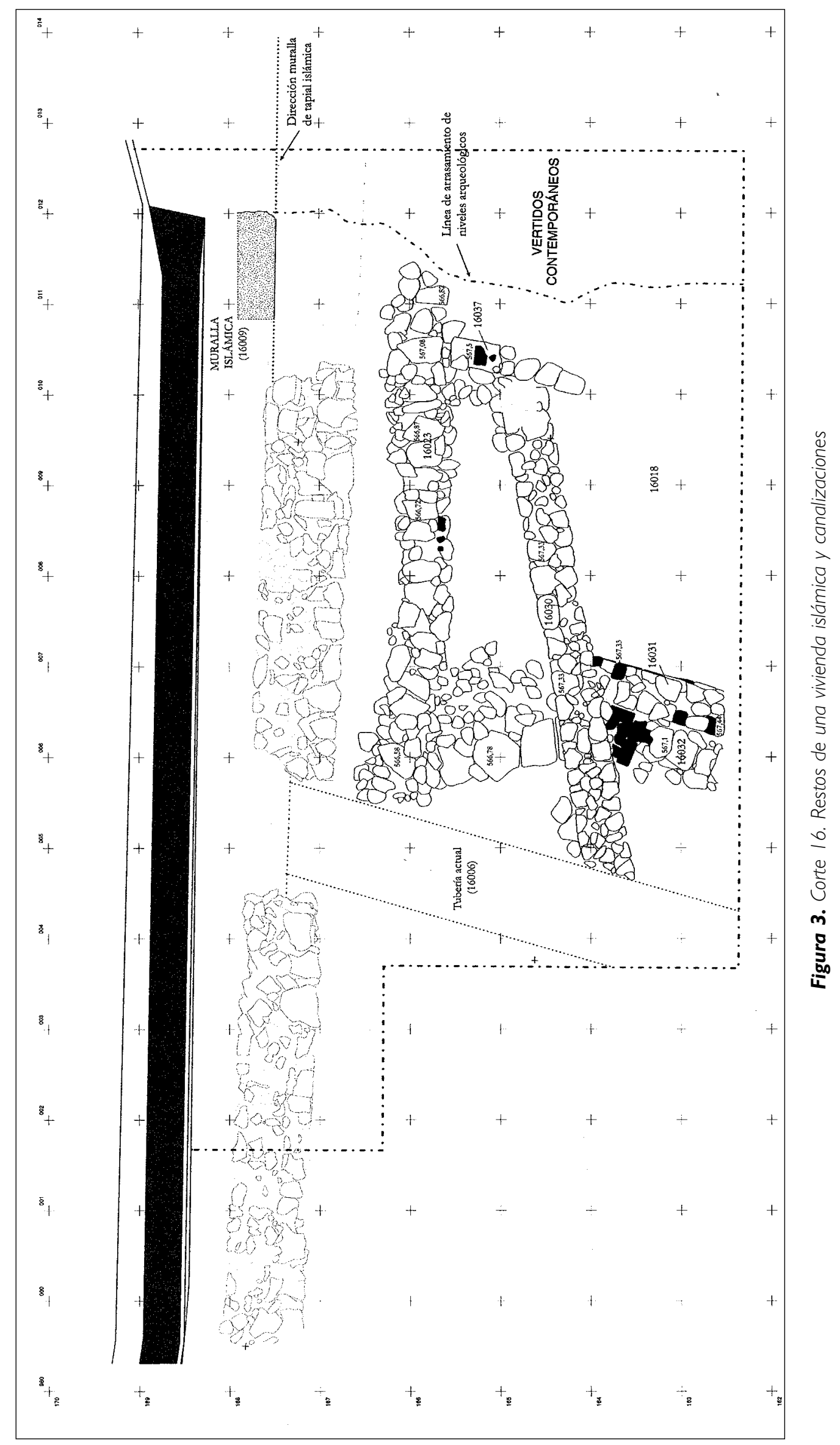




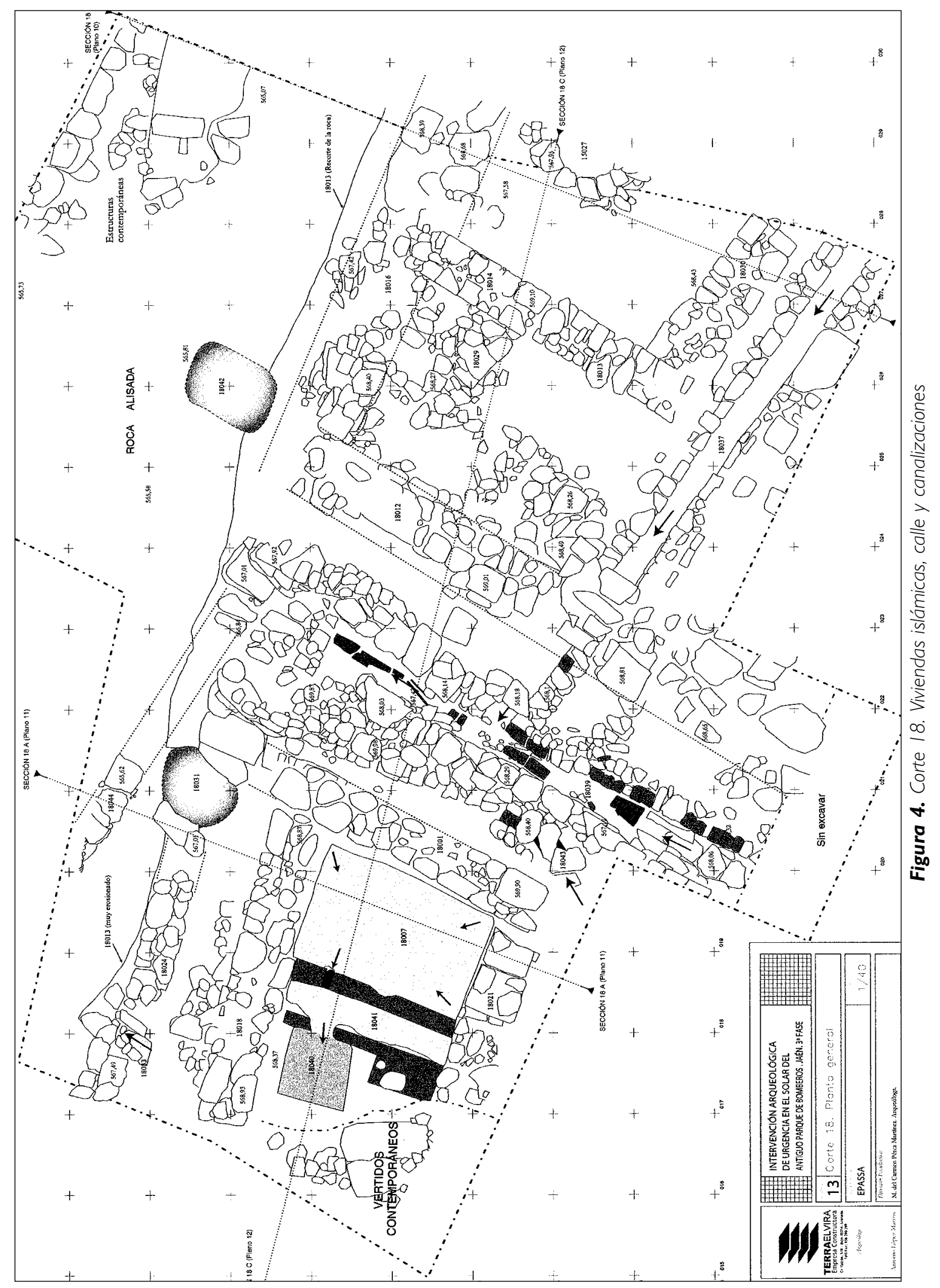




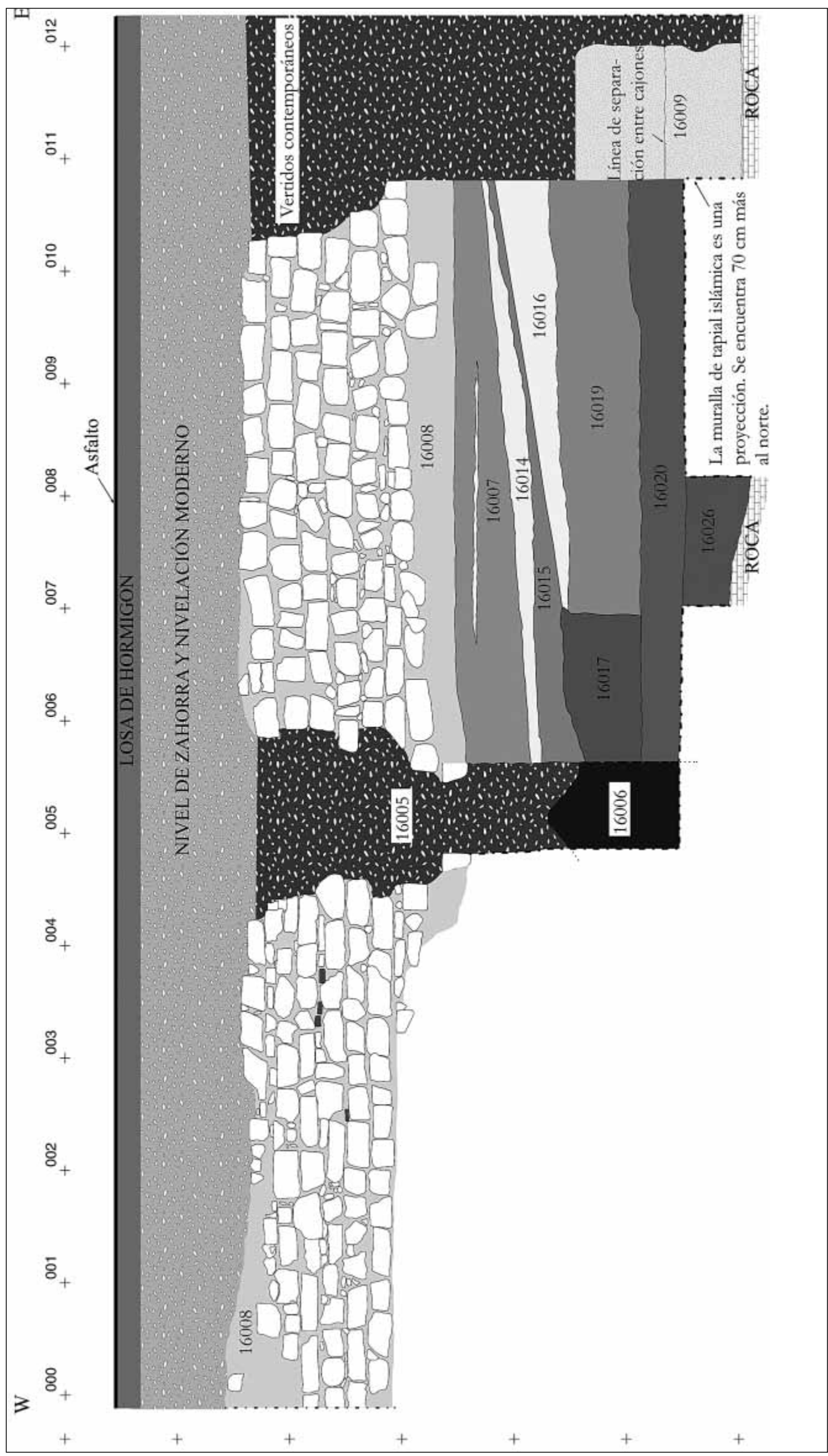

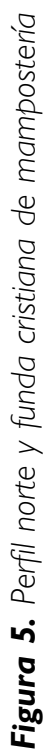




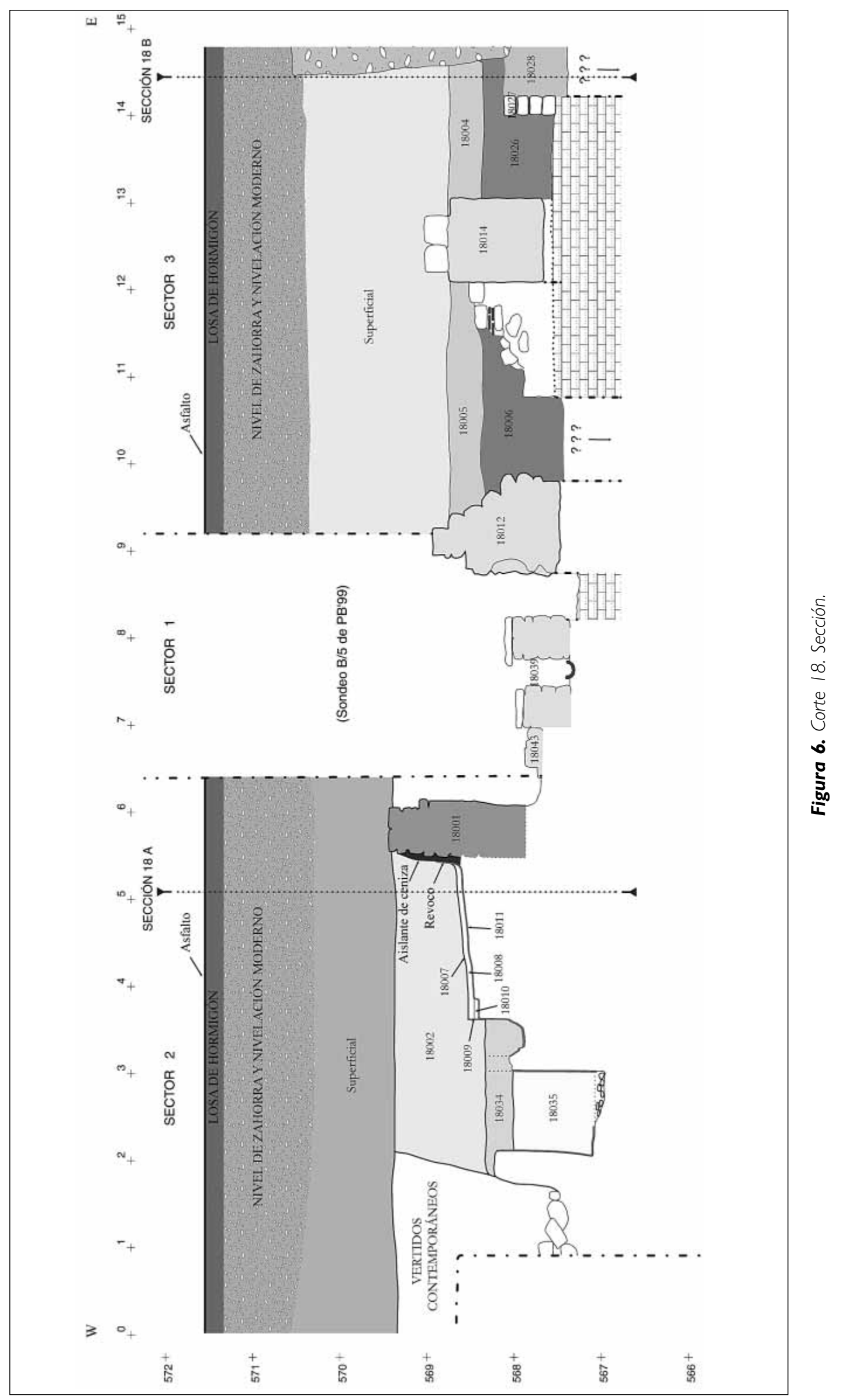




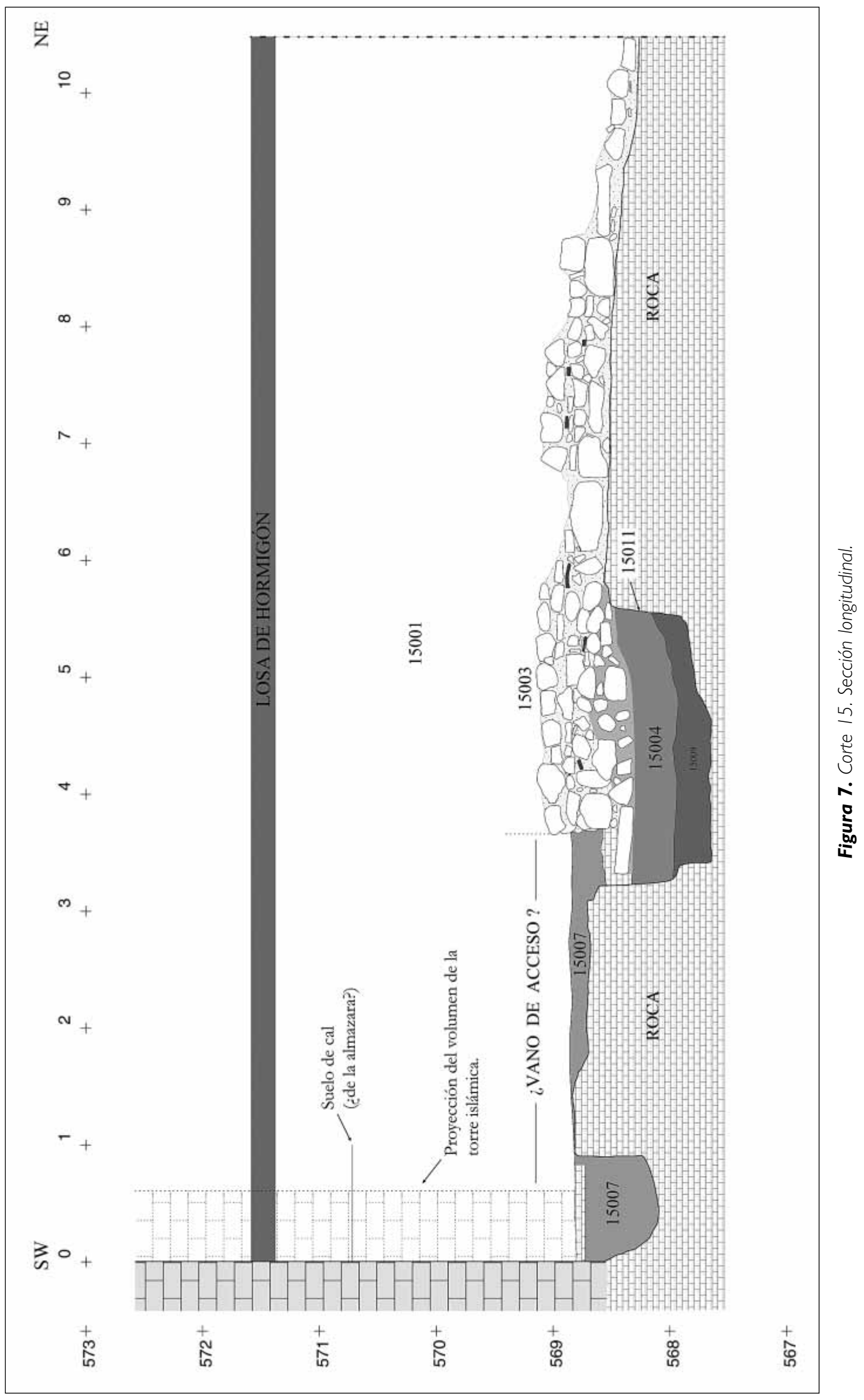




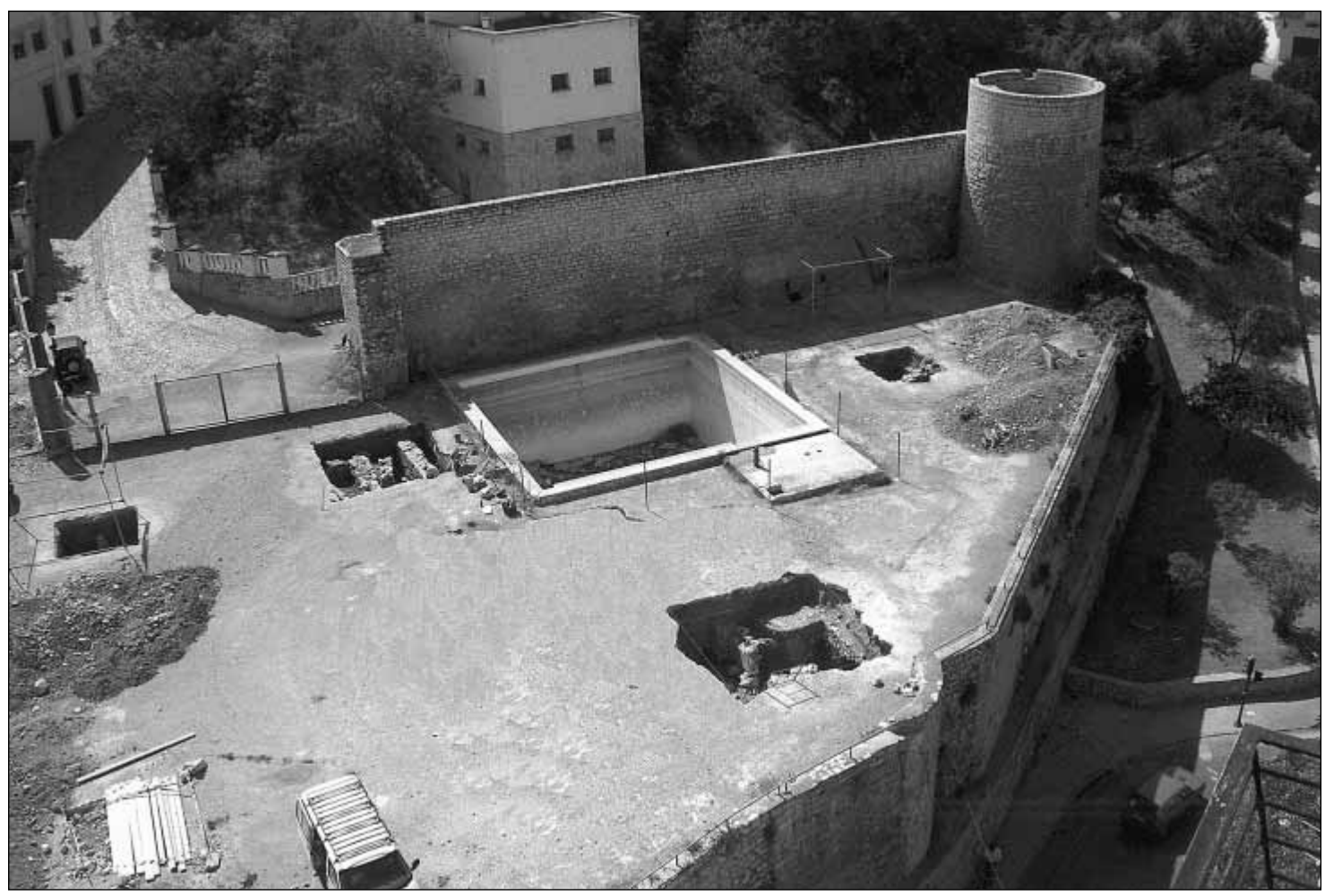

Lámina I. Vista general del solar. Podemos observar la torre en " $D$ " embutida en el muro de contención del solar.

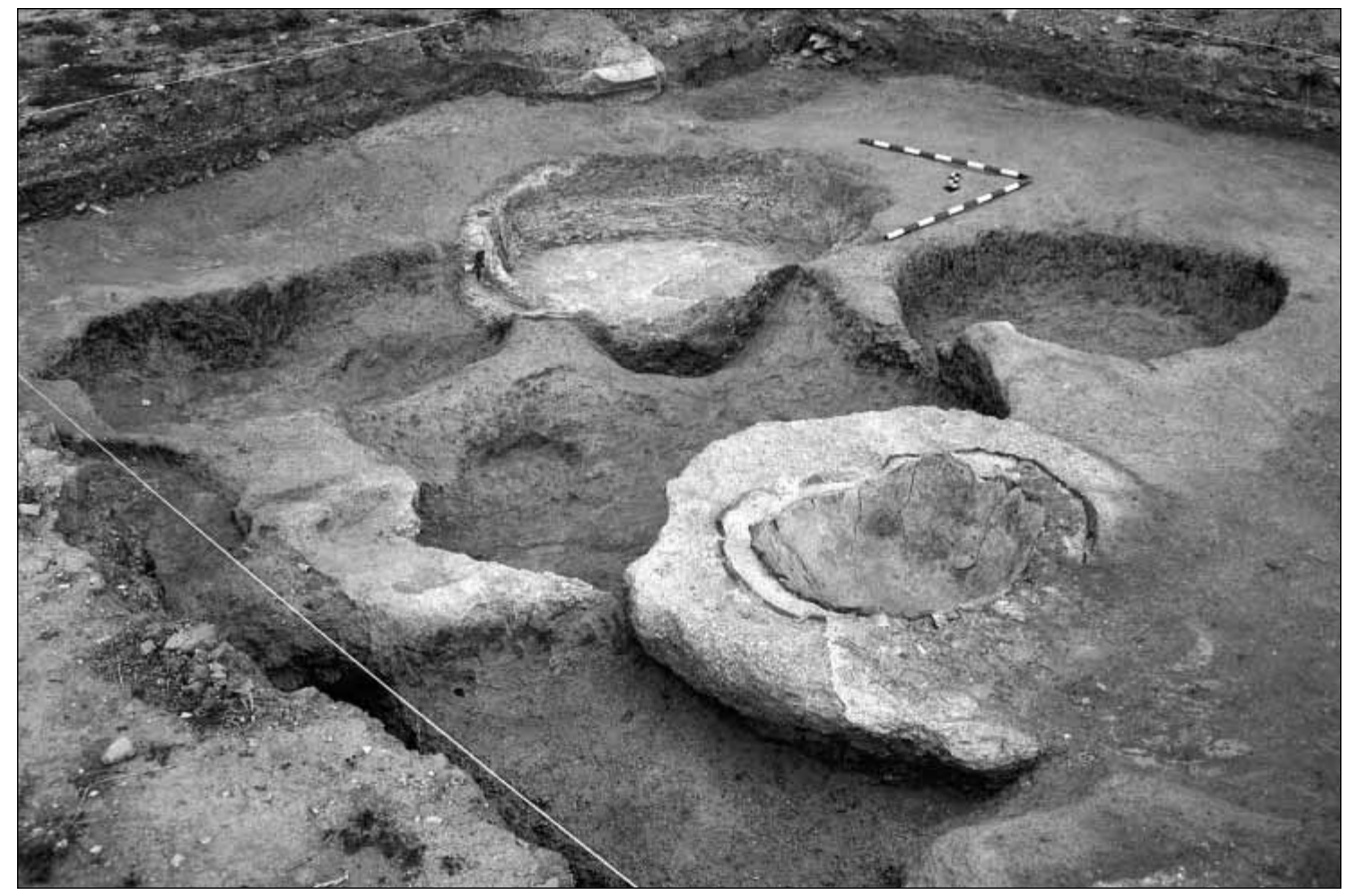

Lámina 2. Corte 4. Estructuras prehistóricas. 


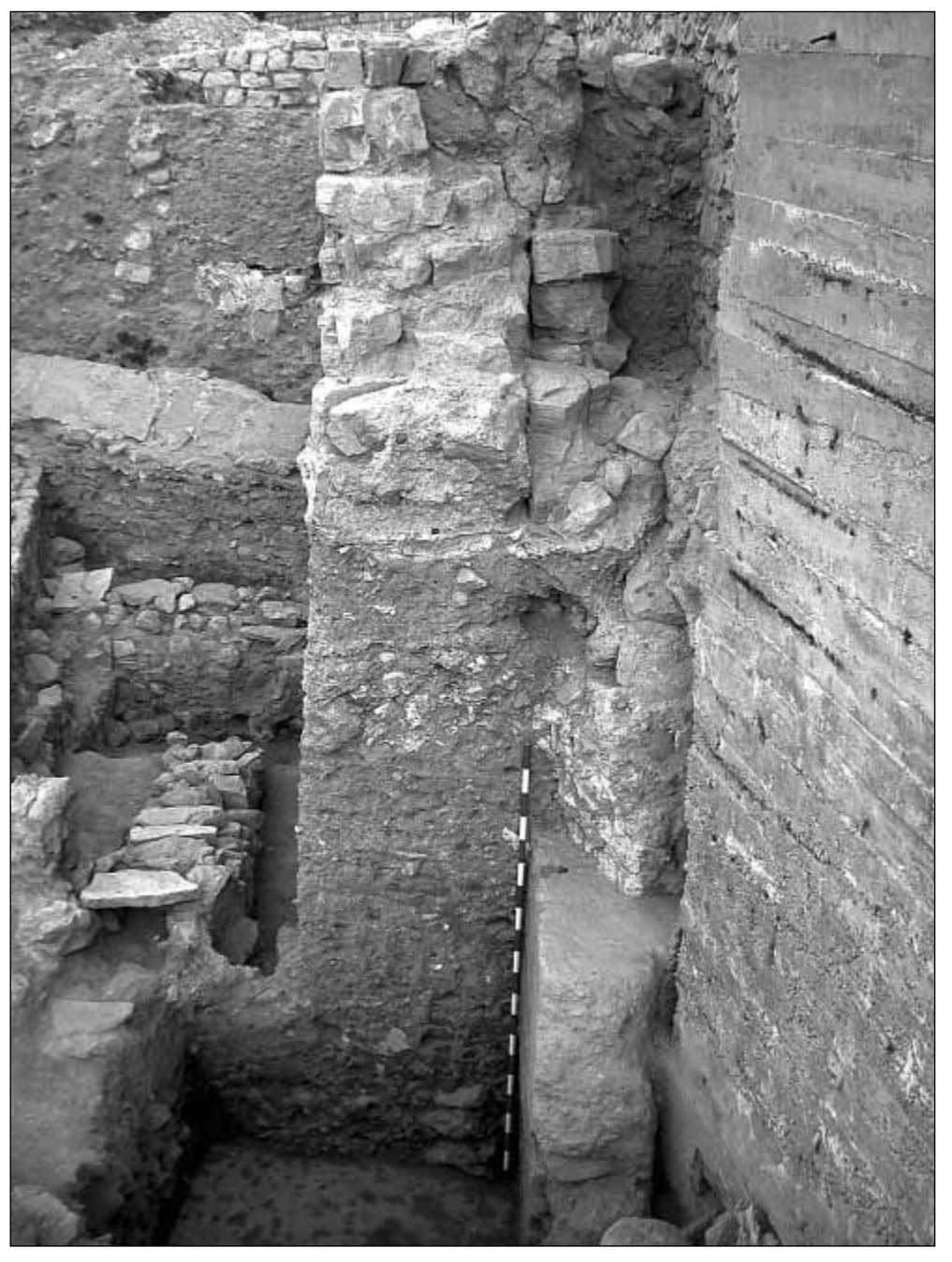

Lámina 3. Alzado de la

muralla con sus distintas fases.

Lámina 4. Corte 17. Estructura de habitación junto a la muralla.

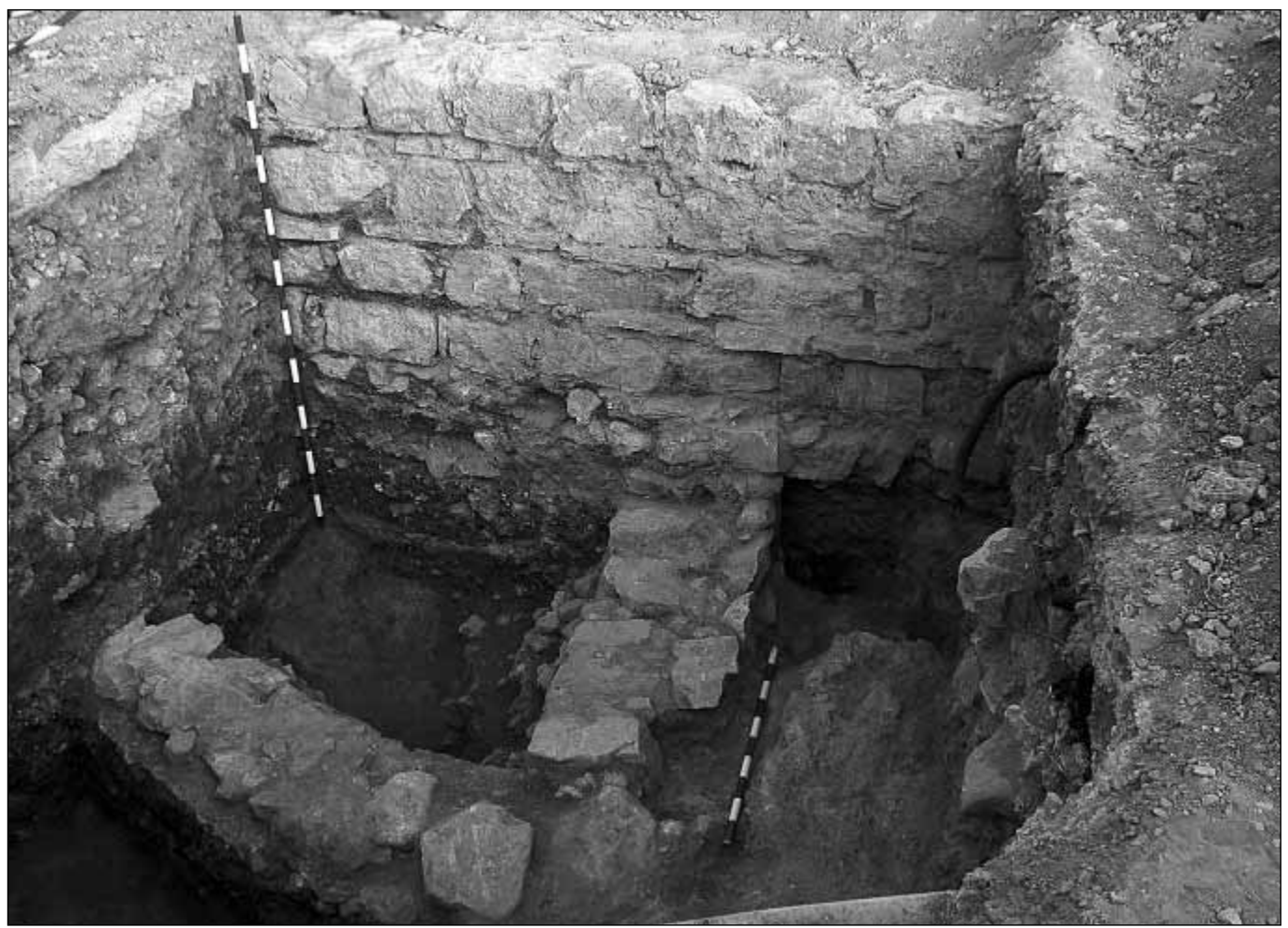



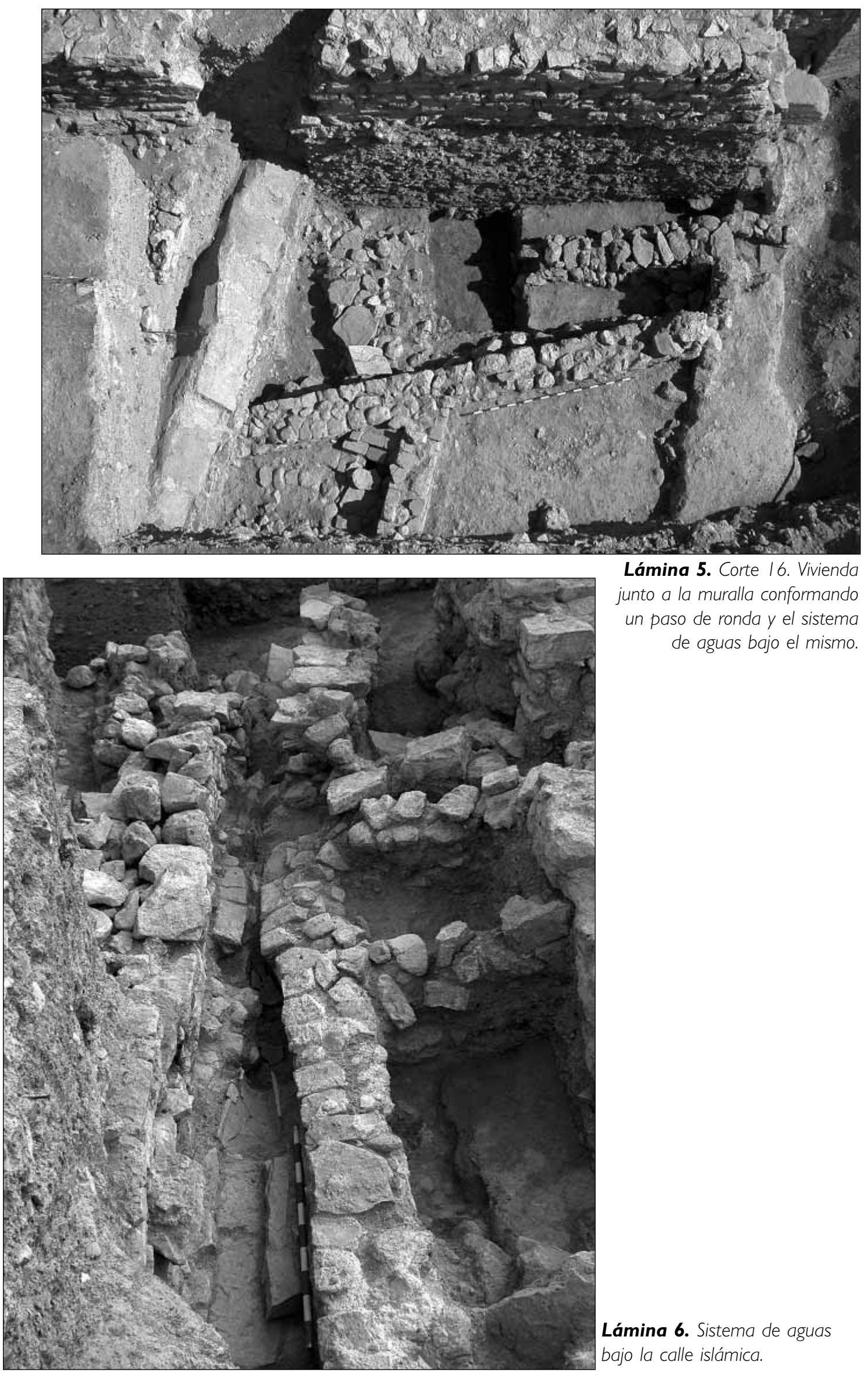

Lámina 5. Corte 16. Vivienda junto a la muralla conformando un paso de ronda y el sistema de aguas bajo el mismo.

Lámina 6. Sistema de aguas bajo la calle islámica. 


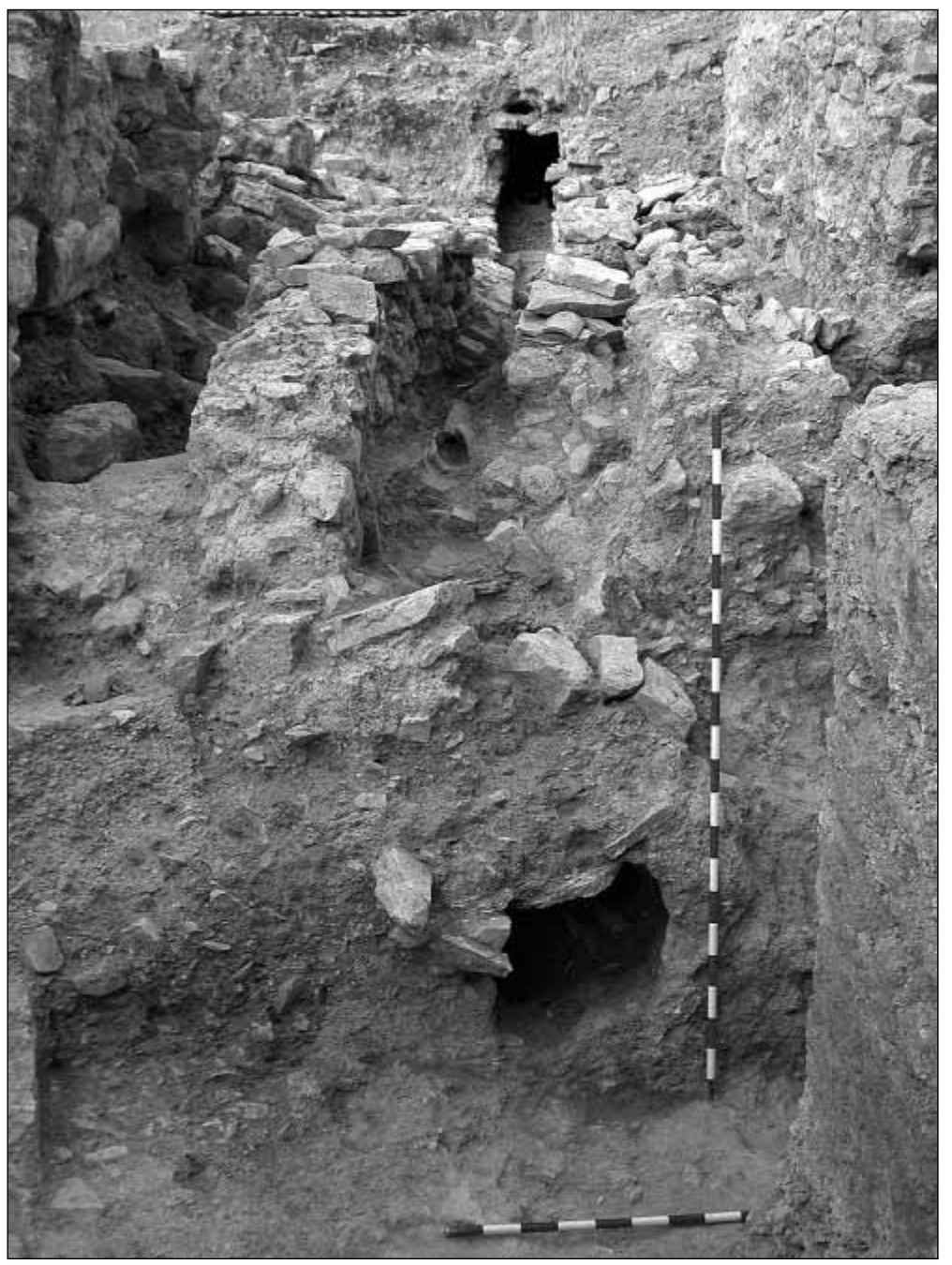

Lámina 7. Sistema de aguas

bajo la calle islámica.

Lámina 8. Molino de aceite.

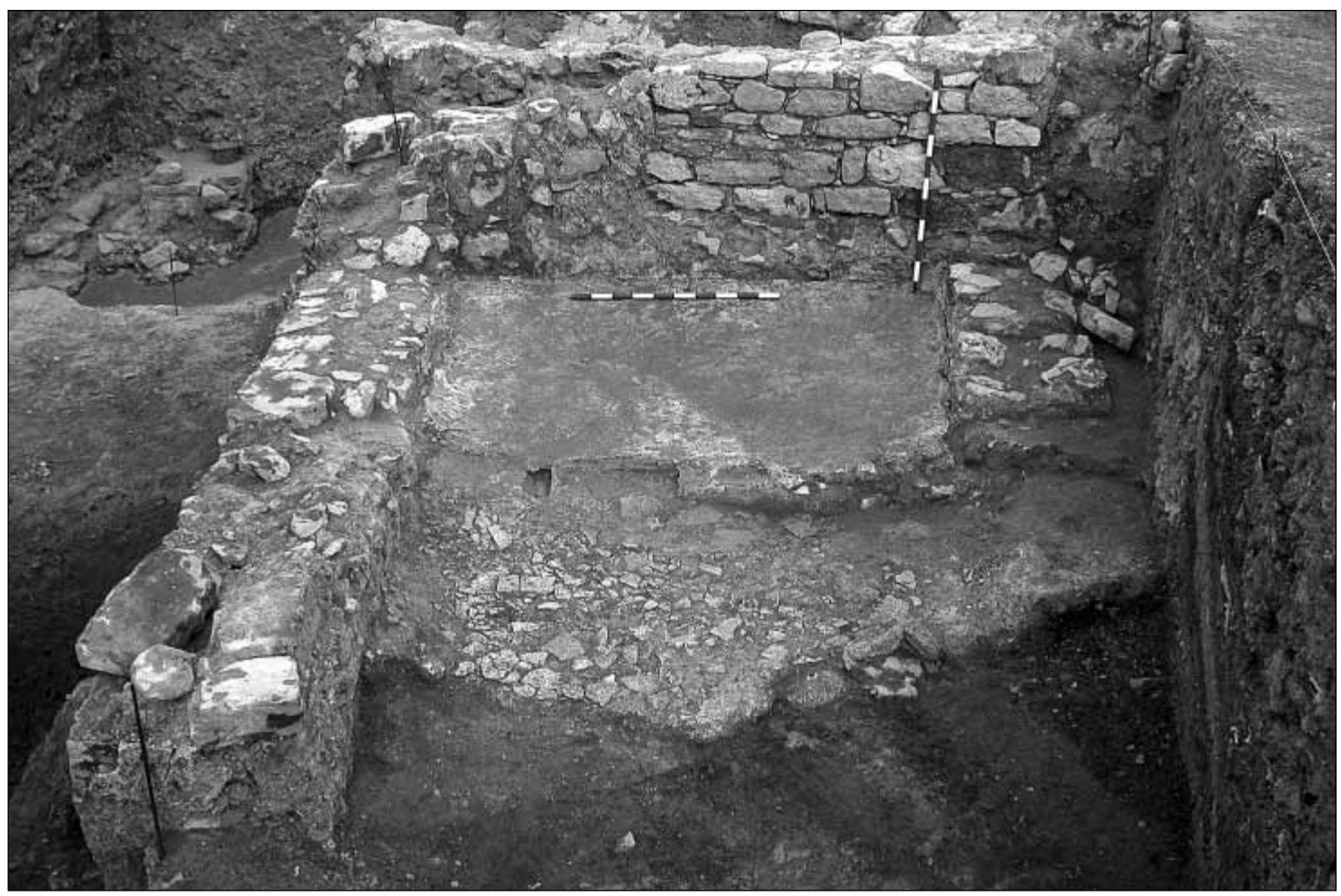




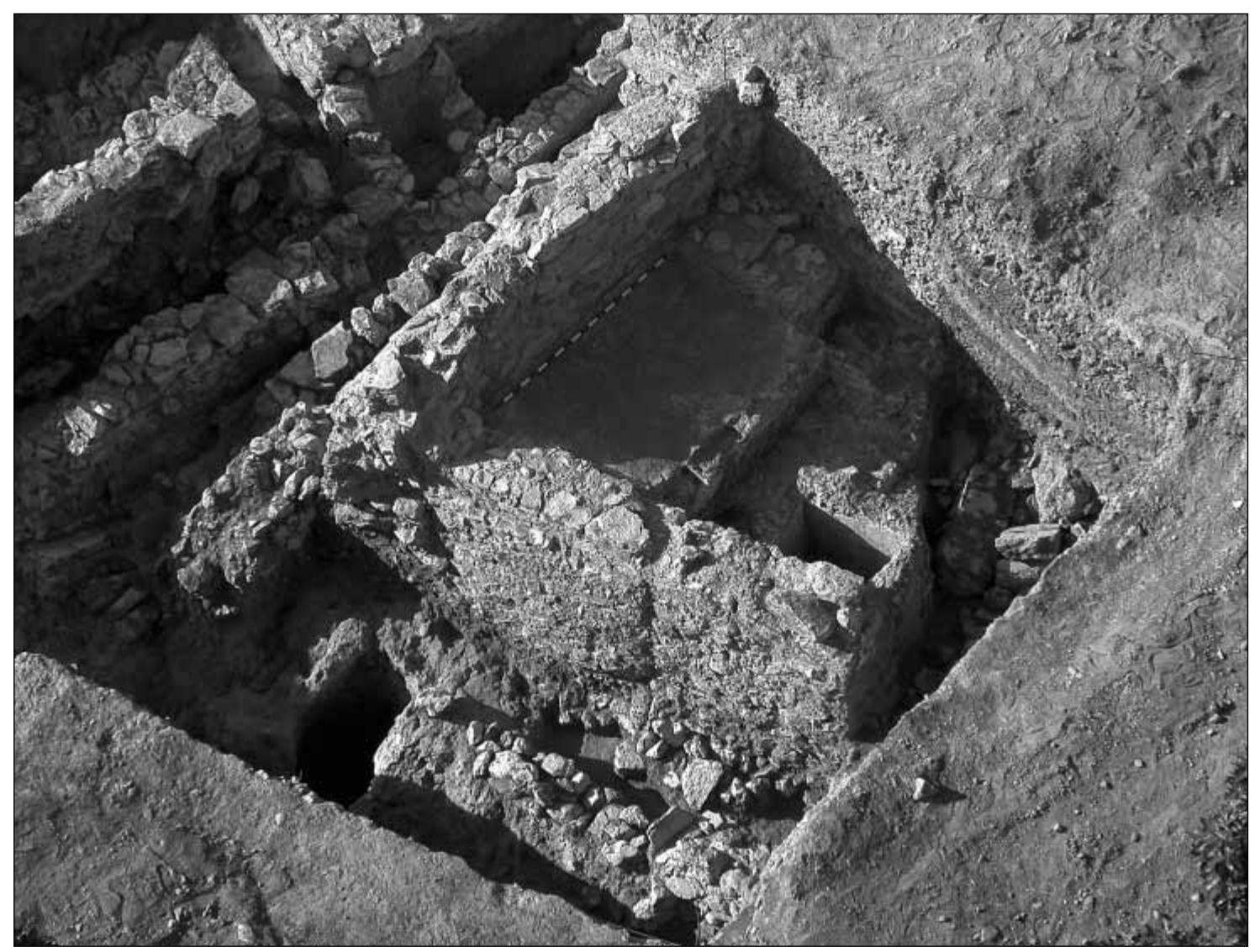

Lámina 9. Vista general de la calle islámica y el molino de aceite cristiano.

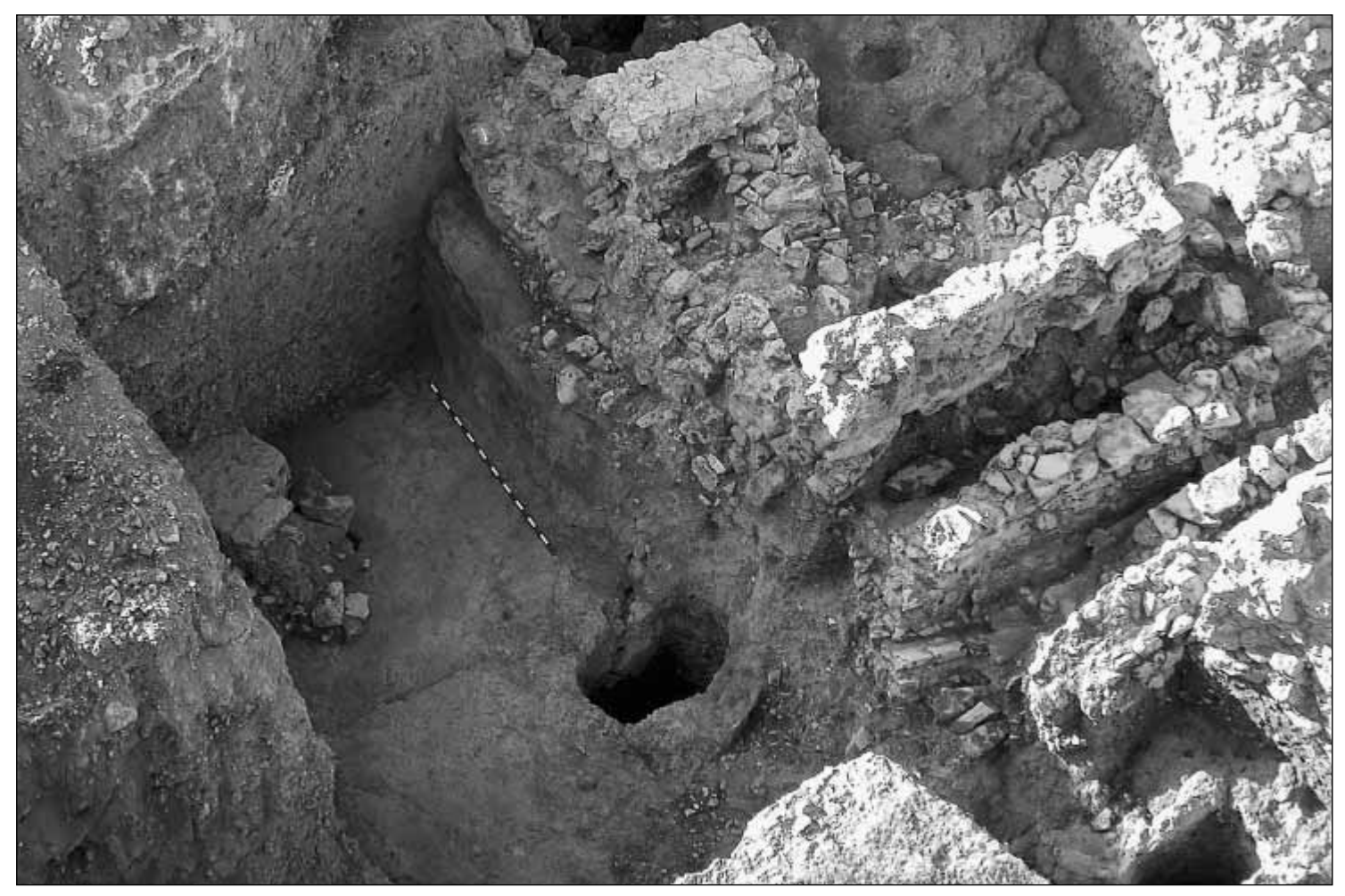

Lámina 10. Corte 15. Posible zona de paso y cava. 


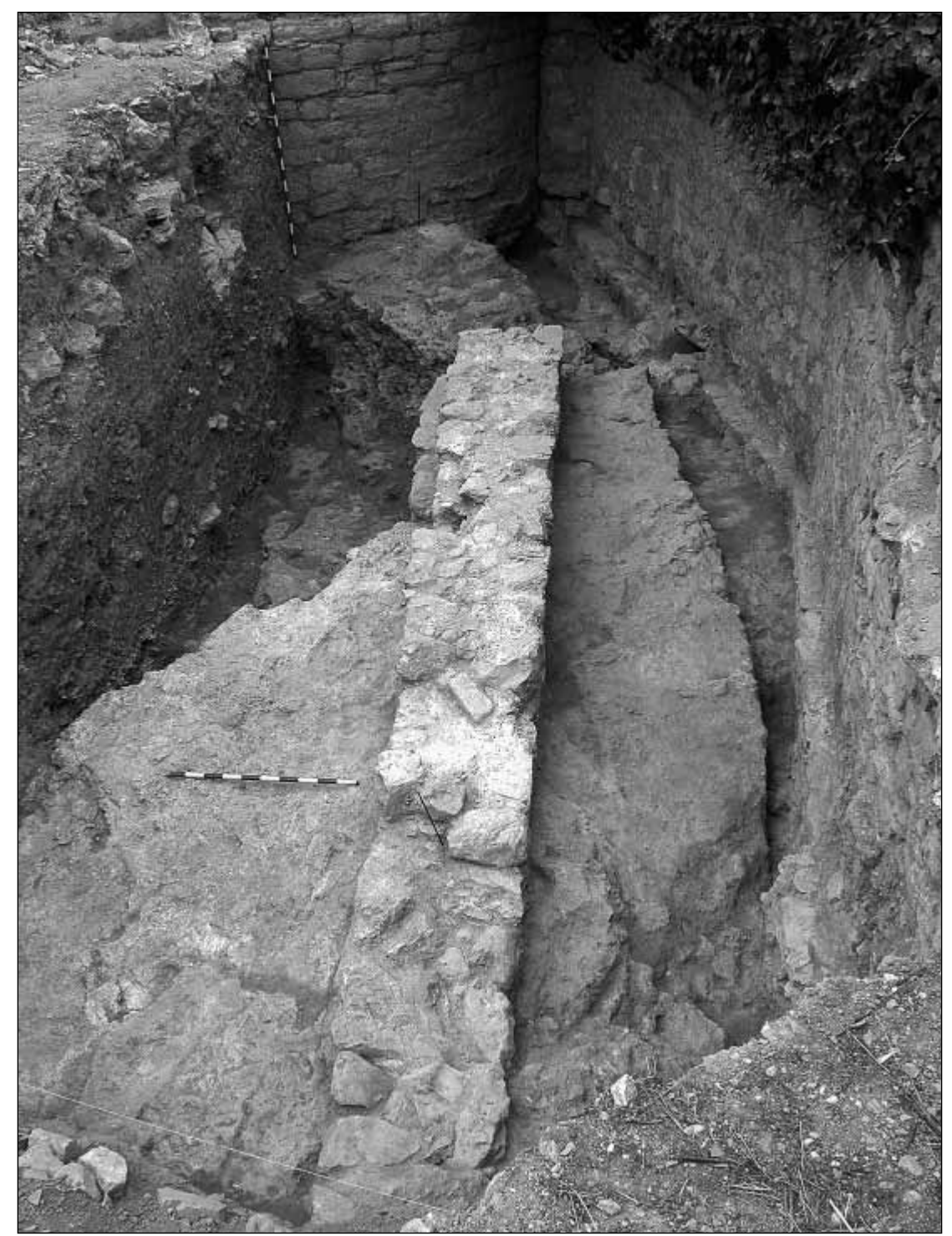

Lámina II. Paso de ronda entre la muralla y las viviendas. 


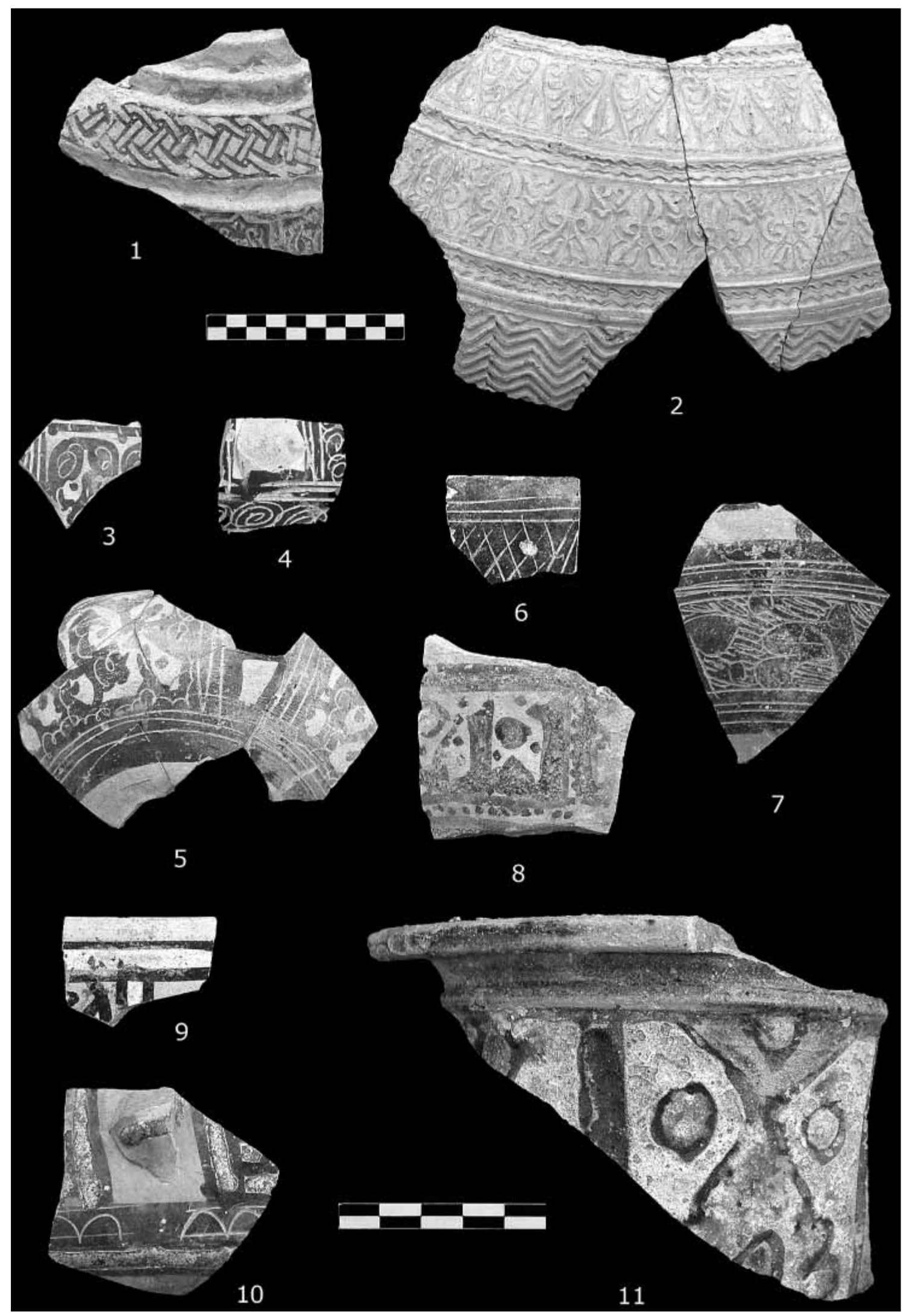

Lámina I2. Materiales. 


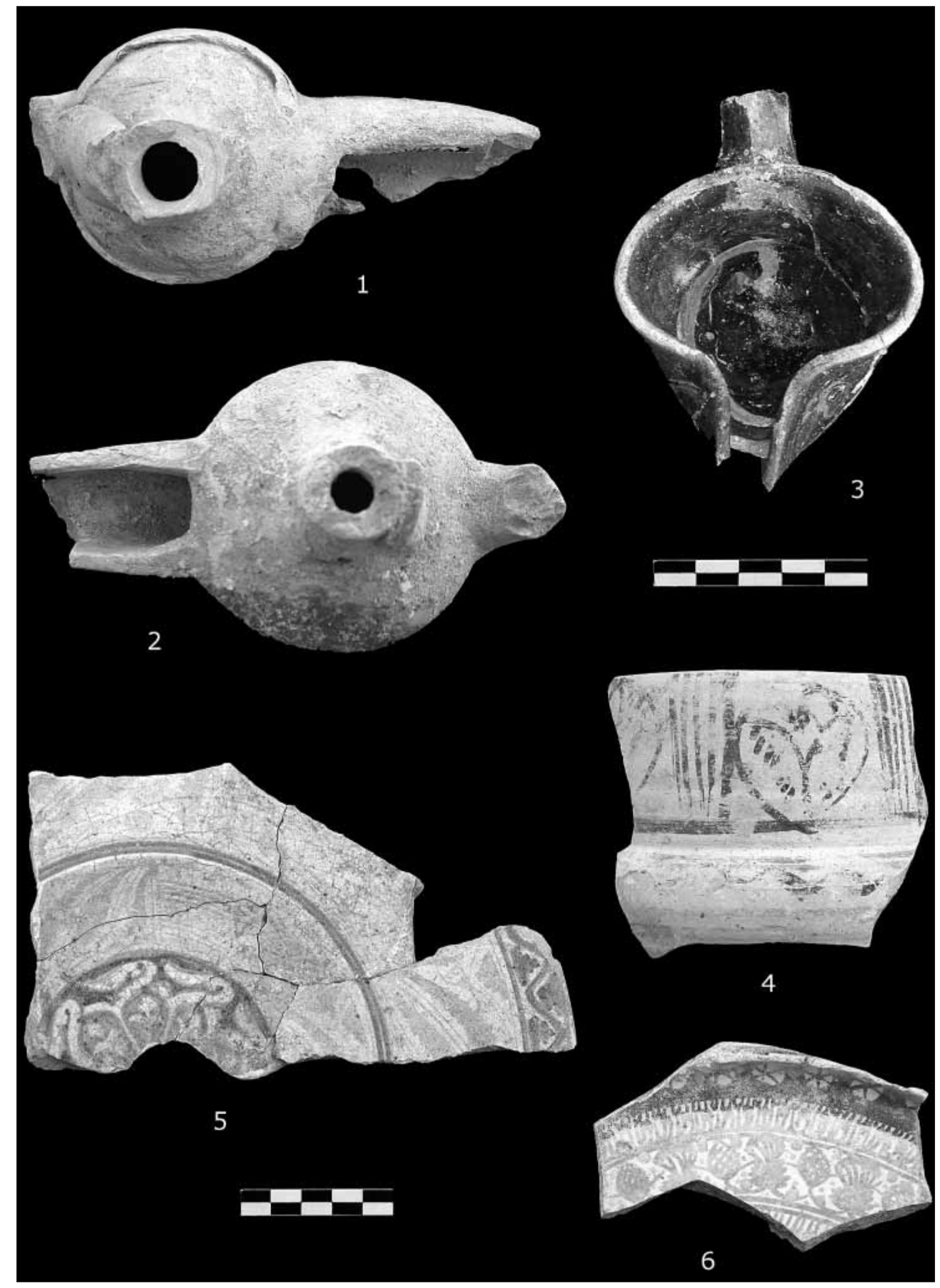

Lámina 13. Materiales. 


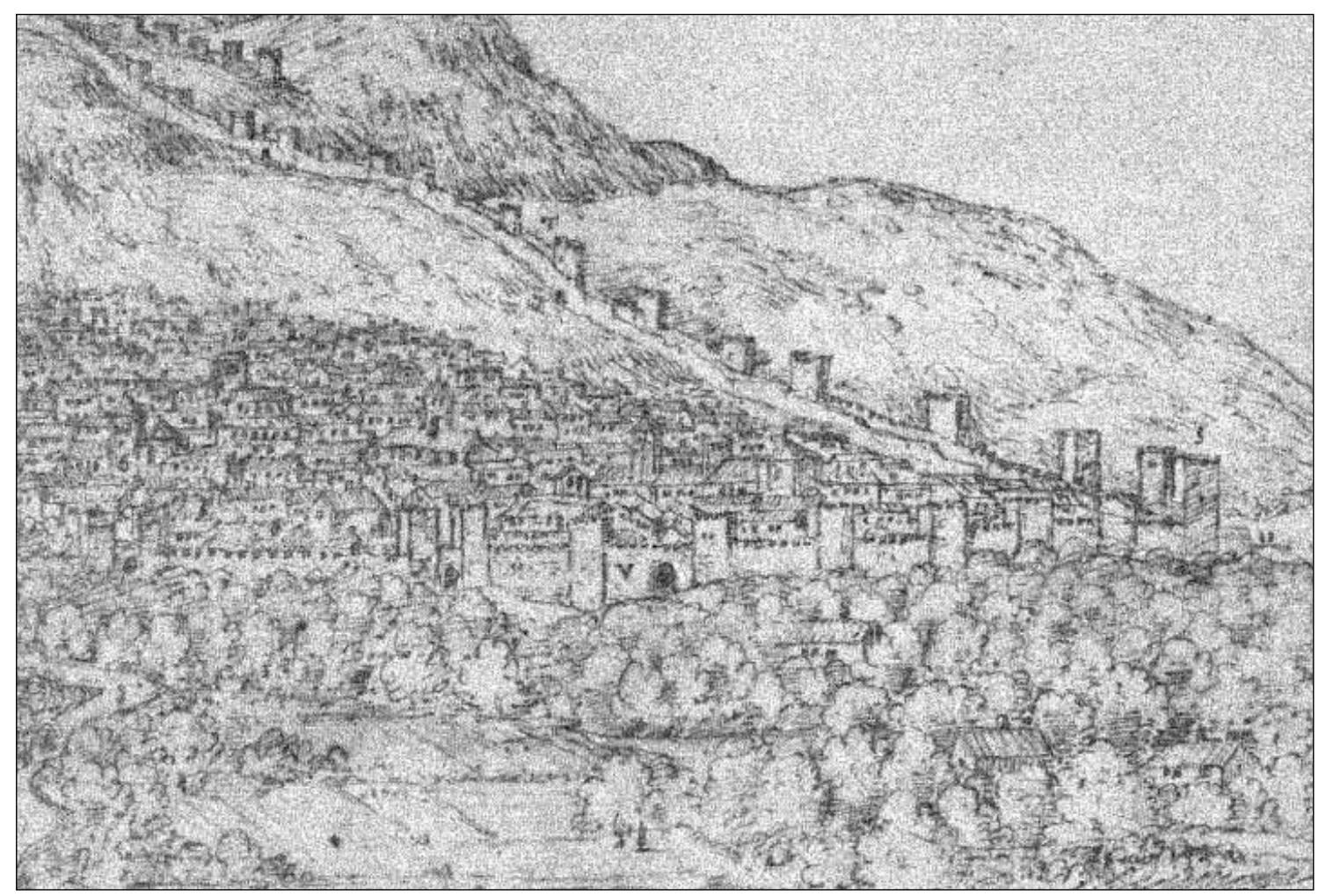

Plano de Anton Van den Wingaerde (1567). Detalle 